\title{
Isothermal Air Ingress Validation Experiments at Idaho National Laboratory: Description and Summary of Data
}

Chang H. Oh

Eung S. Kim

September 2010

The INL is a

U.S. Department of Energy

National Laboratory

operated by

Battelle Energy Alliance

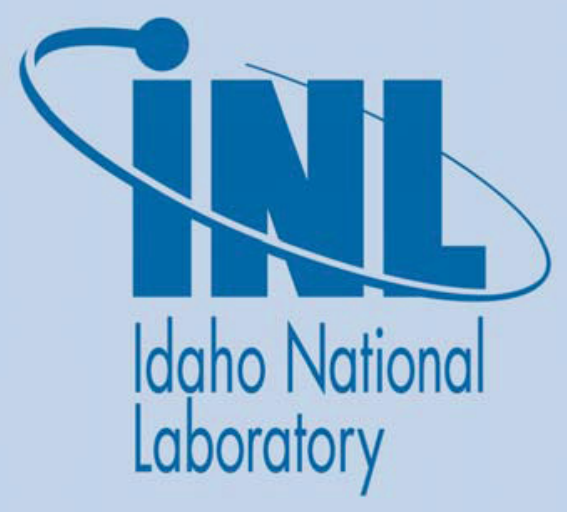

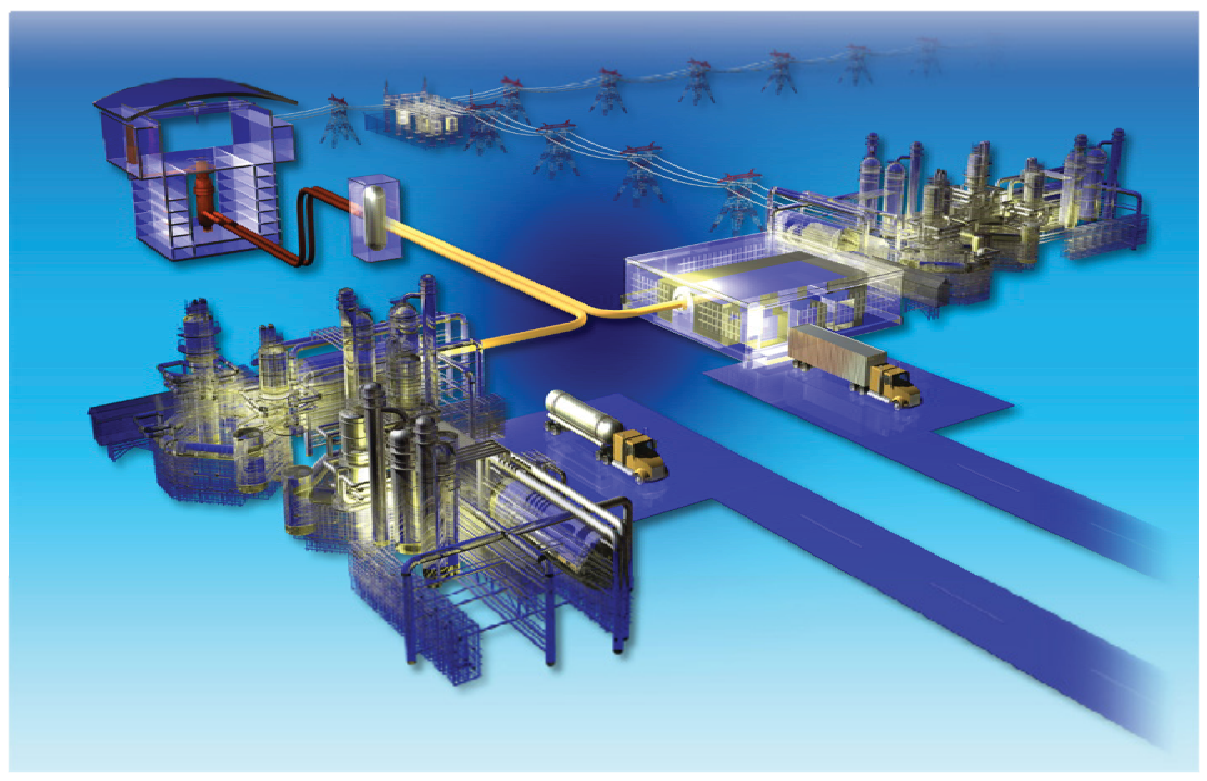




\section{DISCLAIMER}

This information was prepared as an account of work sponsored by an agency of the U.S. Government. Neither the U.S. Government nor any agency thereof, nor any of their employees, makes any warranty, expressed or implied, or assumes any legal liability or responsibility for the accuracy, completeness, or usefulness, of any information, apparatus, product, or process disclosed, or represents that its use would not infringe privately owned rights. References herein to any specific commercial product,

process, or service by trade name, trade mark, manufacturer, or otherwise, does not necessarily constitute or imply its endorsement, recommendation, or favoring by the U.S. Government or any agency thereof. The views and opinions of authors expressed herein do not necessarily state or reflect those of the U.S. Government or any agency thereof. 


\section{Isothermal Air Ingress Validation Experiments at Idaho National Laboratory: Description and Summary of Data}

Chang H. Oh

Eung S. Kim

September 2010

Idaho National Laboratory

Next Generation Nuclear Plant Project

Idaho Falls, Idaho 83415

http://www.inl.gov

Prepared for the

U.S. Department of Energy

Office of Nuclear Energy

Under DOE Idaho Operations Office

Contract DE-AC07-05ID14517 

Next Generation Nuclear Plant Project

\section{Isothermal Air Ingress Validation Experiments at Idaho National Laboratory: Description and Summary of Data}

INL/EXT-10-19727

September 2010

Approved by:

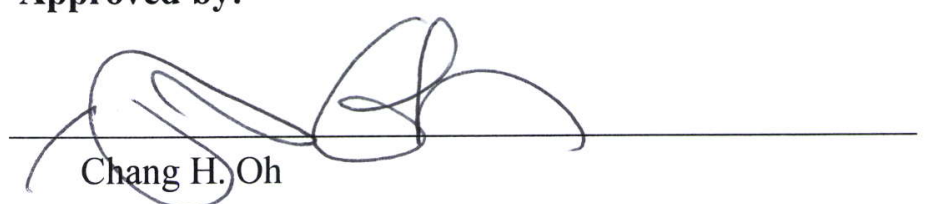

Author

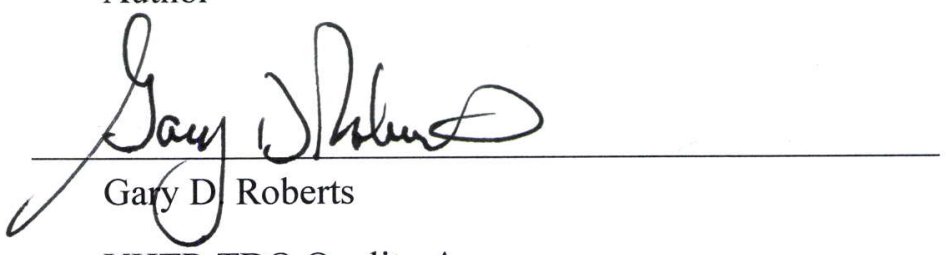

VHTR TDO Quality Assurance
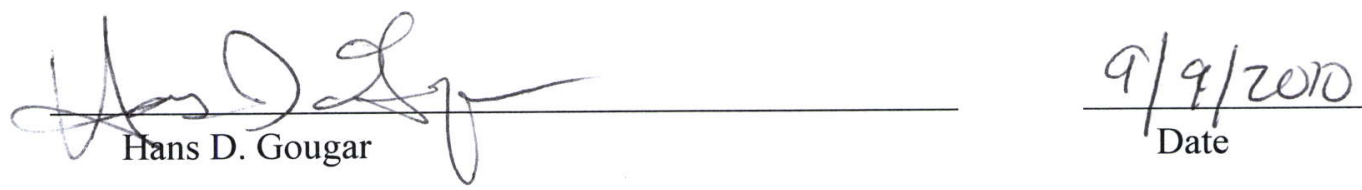

VHTR TDO Technical Deputy Director

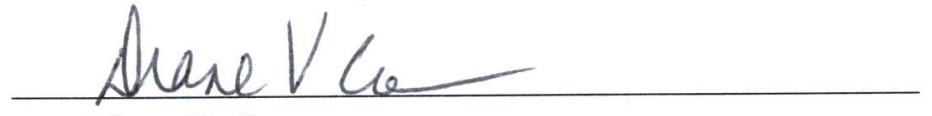

Diane V. Croson
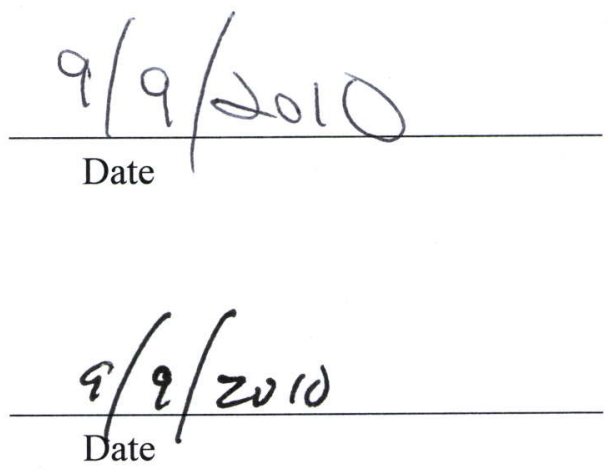

VHTR TDO Deptuty Director

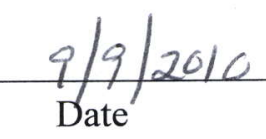




\section{EXECUTIVE SUMMARY}

Idaho National Laboratory performed air ingress experiments as part of validating computational fluid dynamics code (CFD). An isothermal stratified-flow experiment was designed and set to understand stratified-flow phenomena in the very high temperature gas cooled reactor (VHTR) and to provide experimental data for validating computer codes. The isothermal experiment focused on three flow characteristics unique in the VHTR air-ingress accident: stratified flow in the horizontal pipe, stratified flow expansion at the pipe and vessel junction, and stratified flow around supporting structures. Brine and sucrose were used as heavy fluids, and water was used to represent light fluids. The density ratios were changed between 0.87 and 0.98 . This experiment clearly showed that a stratified flow between heavy and light fluids is generated even for very small density differences. The code was validated by conducting blind CFD simulations and comparing the results to the experimental data. A grid sensitivity study was also performed based on the Richardson extrapolation and the grid convergence index method for modeling confidence. As a result, the calculated current speed showed very good agreement with the experimental data, indicating that the current CFD methods are suitable for predicting density gradient stratified flow phenomena in an air-ingress accident.

\section{RESEARCH OBJECTIVES}

The major objective of this project is to understand key phenomena in an VHTR air-ingress accident and to provide ideas for air-ingress mitigation. To achieve this goal, the following analyses and

experiments were planned and conducted in FY 2010 as a level 4 milestone.

- CFD analyses were planned and carried out for understanding density gradient driven stratified flow in the air-ingress accident. The analyses were especially focused on the effect of stratified flow on the natural circulation patterns after onset of natural circulation.

- Stratified flow experiments were designed and performed in order to support previous air-ingress analyses and to validate the computational methods used. 


\section{CONTENTS}

EXECUTIVE SUMMARY

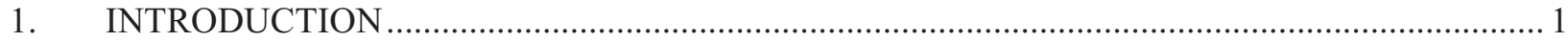

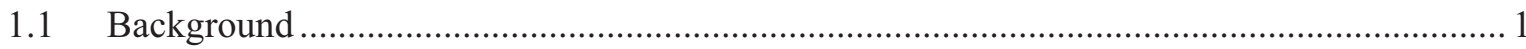

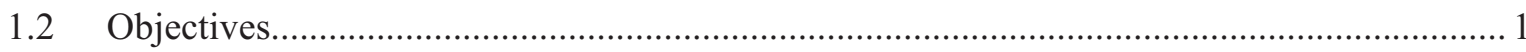

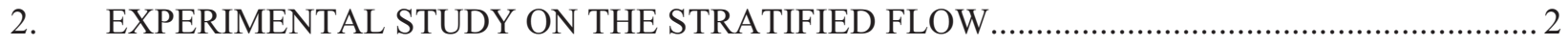

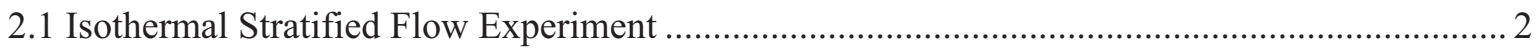

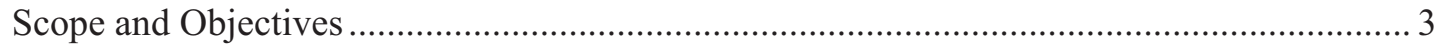

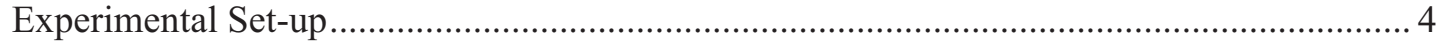

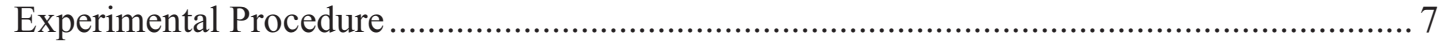

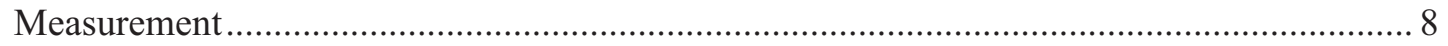

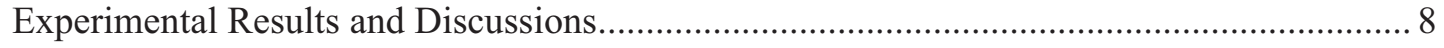

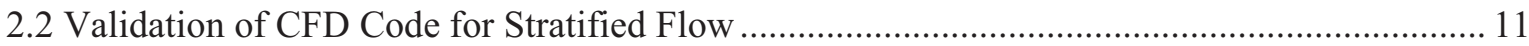

Preliminary CFD Result and Validation Study with Experiment ....................................... 11

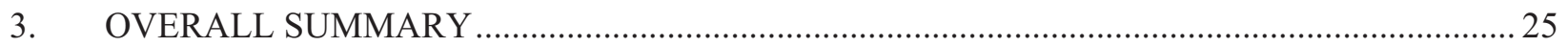

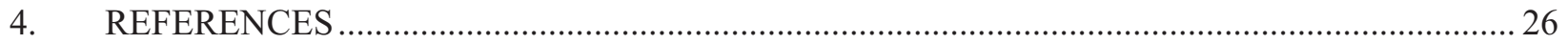

Appendix A Isothermal Stratified Flow Experiment Facility Schematics .............................................28

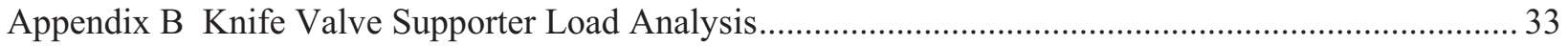

\section{FIGURES}

Figure 2-1. Flows of interest in the isothermal full-break experiment

Figure 2-2. Comparisons between previous gravity current studies and VHTR air-ingress

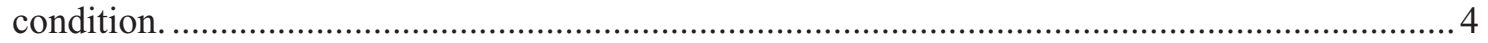

Figure 2-3. Schematics of isothermal DEGB experiment................................................................... 5

Figure 2-4. Isothermal stratified flow experimental set-up for brine-water............................................ 5

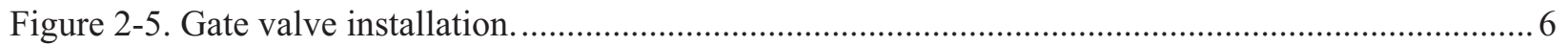

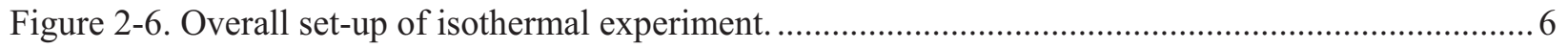

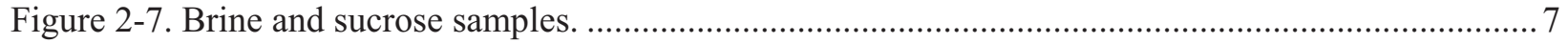

Figure 2-8. Progress of gravity current and stratified flow (water-sucrose, density ratio $=0.866$

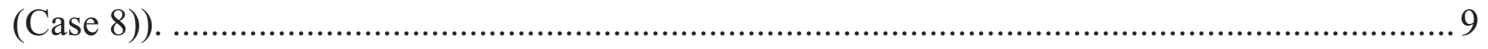

Figure 2-9. Experimental results (traveling distance vs. time). ............................................................. 10

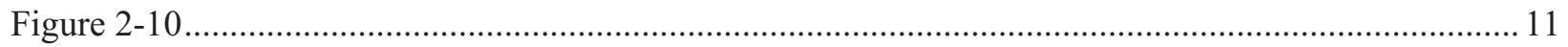

Figure 2-10. Overall geometry with normal mesh and side view from symmetry surface...................... 11

Figure 2-11. Initial brine-water mass fraction (red: brine, blue: water) ................................................ 13

Figure 2-12. Visualization of brine water intrusion from tilted top view at marching time frame............ 14 
Figure 2-13. The correlation of density and ratio of sucrose viscosity to water viscosity...................... 15

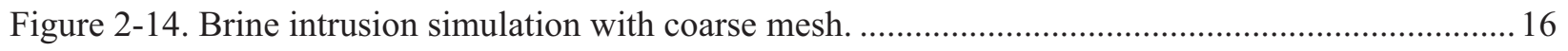

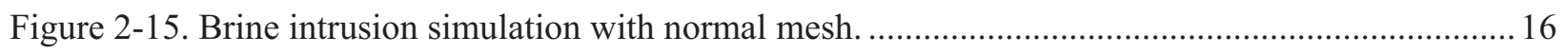

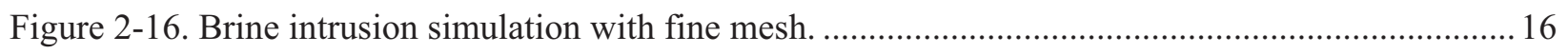

Figure 2-17. Brine mass fraction at the bottom as time marches until $7 \mathrm{sec}$ (normal, coarse mesh)......... 17

Figure 2-18. Front speed calculation in different mesh (coarse, normal, and fine). ................................ 18

Figure 2-19. Correlation of grid spacing and prediction value in grid convergence study....................... 19

Figure 2-20. Simulated front-head speed and calculated front-head speed at zero grid spacing with

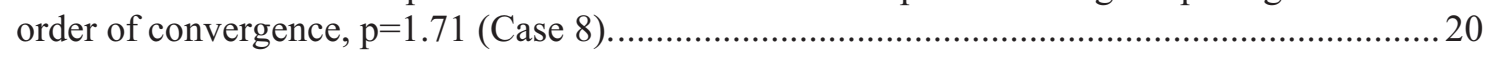

Figure 2-21. Comparison of CFD result and experiment measurement of front head speed.....................2

Figure 2-22. Plot of experimental data with uncertainty band and CFD prediction value with code uncertainty band comparison between experiment measurement and previous model

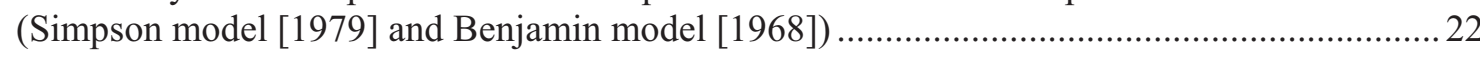

Figure 2-23. Measured front head speed $U$, scaled with $\left(g^{\prime} d 1\right) 1 / 2$, as a function of $d 1 / D$ of INL

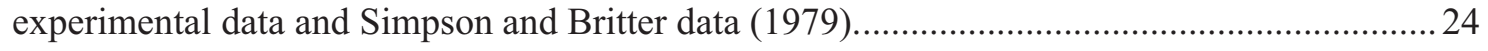

Figure A-1. Double-ended guillotine break facility assembly with knife gate valve. ............................. 30

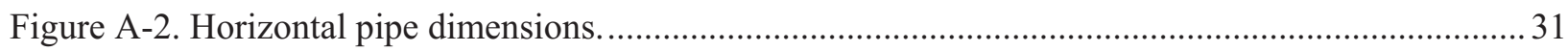

Figure A-3. Flanged tank dimensions. Tanks have covers on both top and bottom to facilitate

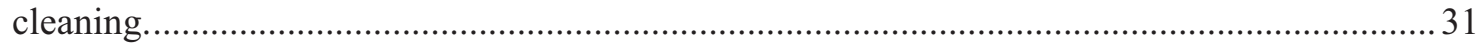

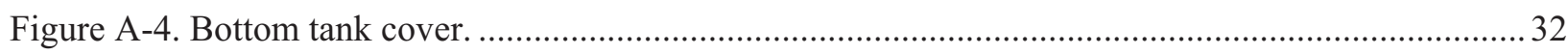

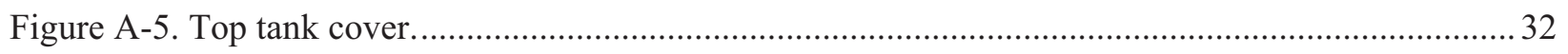

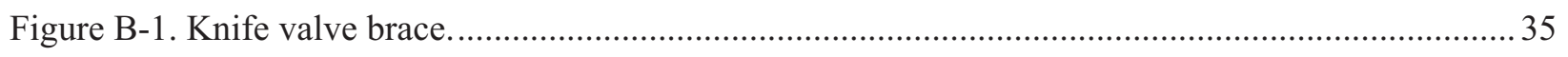

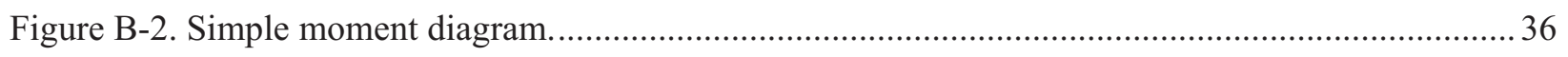

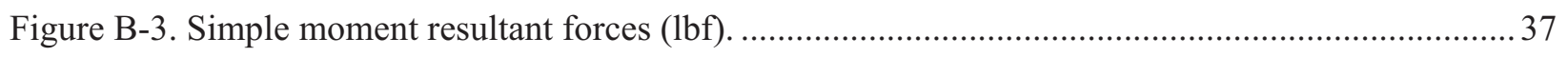

Figure B-4. Resultant forces from simulated loading (lbf) ............................................................. 38

Figure B-5. Local frame stresses from simulated load (psi) .............................................................. 39

\section{TABLES}

Table 2-1. Previous and current validation data for air-ingress analyses................................................. 2

Table 2-2. Experimental conditions and case summary ...................................................................... 7

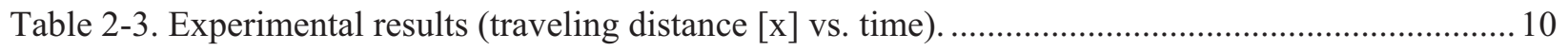

Table 2-4. Comparisons of current speeds between experiment and Benjamin's theoretical model.......... 10

Table 2-5. Front head speed calculation at different normalized spacing ............................................... 19

Table 2-6. Uncertainty of front-head speeds from experiments and CFD code calculations. ...................22 


\section{ACRONYMS}

CFD computational fluid dynamics

DEGB double-ended guillotine break

GCI Grid Convergence Index

GTHTR Gas Turbine High Temperature Reactor

GTMHR gas-turbine modular helium reactor

HTGR high temperature gas-cooled reactor

INL Idaho National Laboratory

LOCA loss-of-coolant accident

NGNP Next Generation Nuclear Plant

VHTR very high temperature gas-cooled reactor 


\section{Isothermal Air Ingress Validation Experiments at Idaho National Laboratory: Description and Summary of Data}

\section{INTRODUCTION}

A loss-of-coolant accident (LOCA) is considered a noteworthy event for a very high temperature reactor (VHTR). Following helium depressurization, it is anticipated that, unless countermeasures are taken, air ingress may occur, depending on the design, the location, and the orientation of the break.

The U.S. Department of Energy is performing research and development that focuses on key phenomena important during challenging scenarios that may occur in the Next Generation Nuclear Plant (NGNP)/Generation IV VHTR. Phenomena Identification and Ranking Table studies have identified the air ingress event, following on the heels of a VHTR depressurization, as very important (Schultz et al., 2006). Consequently, the development of advanced air ingress-related models and verification and validation requirements are high priorities for the NGNP Program.

\subsection{Background}

The VHTR is a graphite-moderated, uranium-fueled, helium-cooled reactor using a direct or indirect gas cycle to convert the heat generated by nuclear fission into electrical energy by means of a helium turbogenerator. High temperature gas-cooled reactor (HTGR) technology has been researched and developed since the 1950s. The VHTR produces a higher outlet temperature than the HTGR. VHTRs work on the principle of passing a cooling gas through the core, then running the heated gas directly to a steam generator or a gas turbine. VHTRs have been built in Japan and China for their nuclear research. VHTRs have several advantages over light water reactors, including fuel integrity, proliferation resistance, a relatively simple fuel cycle, easy refueling, and modularity to supply electricity to remote areas. Even though gas reactors have been developed in the past with limited success, the innovations of modularity and integrated state-of-the-art safety systems make the VHTR design attractive from a technical and economic perspective.

\subsection{Objectives}

The work summarized in this report is centered on describing the experimental planning, construction, and testing of the isothermal air ingress experiments performed at the Idaho National Laboratory in fiscal year 2010. The original milestone was aimed at only describing the experimental planning, construction, and shakedown testing of the isothermal air ingress experiments. However, the work proceeded at a more rapid rate than anticipated and thus a series of experiments were also performed-which are also reported herein.

The isothermal air ingress experiments were performed to provide validation data for computational fluid dynamics (CFD) software. Consequently, some CFD validation calculations are also reported using the Fluent CFD code - although the major CFD validation effort will be focused on the STAR-CCM+ software at a future time. The Fluent validation calculations given in this report should be viewed as scoping calculations only. 


\section{EXPERIMENTAL STUDY ON THE STRATIFIED FLOW}

Many computational and theoretical works have been carried out to understand what will happen in the actual air-ingress accident. However, validation data are required to support this air-ingress theory and the computational results. Table 2-1 shows the previous and current experimental data used to validate computer codes for air-ingress analyses. This table lists 14 different experimental sets covering diffusion, natural convection, radiation, chemical reaction, and porous media models in the code; however, there is no good data for validation of stratified flow are presently available.

Table 2-1. Previous and current validation data for air-ingress analyses.

\begin{tabular}{|c|c|c|c|c|c|c|c|}
\hline & Test Facility & D & NC & $\mathbf{R}$ & C & $P$ & etc \\
\hline 1 & Pipe Network, NWU & & & & & & $\mathrm{O}$ \\
\hline 2 & Blowdown, NWU & 0 & & & & & 0 \\
\hline 3 & Buncan \& Toor's Experiment & $\mathrm{O}$ & & & & & \\
\hline 4 & Inverse U-tube single/multiple channel test & $\mathrm{O}$ & 0 & & & & \\
\hline 5 & Ogawa's circular tube test & & & & 0 & & \\
\hline 6 & Takahashi's annular tube test & & & & 0 & & \\
\hline 7 & VENTURA pebble bed test & & & & $\mathrm{O}$ & 0 & \\
\hline 8 & Inverse U-tube air ingress experiment & $\mathrm{O}$ & $\mathrm{O}$ & & $\mathrm{O}$ & & \\
\hline 9 & HTTR simulated air ingress experiment & $\mathrm{O}$ & $\mathrm{O}$ & & 0 & & 0 \\
\hline 10 & Vertical slot experiment & 0 & 0 & & & & \\
\hline 11 & NACOK natural convection test & & $\mathrm{O}$ & & & $\mathrm{O}$ & \\
\hline 12 & SANA-1 afterheat removal test & & & & & $\mathrm{O}$ & \\
\hline 13 & HTTR RCCS mockup test & & $\mathrm{O}$ & $\mathrm{O}$ & & & \\
\hline 14 & SNU RCCS test & & 0 & 0 & & & \\
\hline
\end{tabular}
D: Diffusion NC: Natural Convection
R: Radiation
C: Chemical Reaction
P: Porous Media

A number of sets of experiments were planned to understand stratified flow phenomena and validate the computer codes with physical models. This experimental work covers a separate effort to couple effects related to the stratified flow.

\subsection{Isothermal Stratified Flow Experiment}

The current section describes separate-effect experiments for understanding stratified flow phenomena in the air-ingress accident and for generating data for validation of computer codes, including CFD codes or system analysis codes. This experiment is aimed at the phenomena that occur for a doubleended-guillotine break (DEGB) scenario. Although the DEGB scenario is recognized as a beyond design basis accident (BDBA) scenario, stratified flow air ingress experiments are being conducted to study this experimental break configuration because: (i) it is a limiting event, i.e., it is the largest break size and traditionally safety research performed by the U.S. Nuclear Regulatory Commission has always focused on limiting events, and (ii) the geometry is considerably simpler than the more likely small leak scenarios. . 
Density gradient driven flow is a new issue in the VHTR safety analysis field. The detailed mechanisms for the whole scenario have not yet been fully understood or validated up to the level of satisfaction for the safety analyses. This section summarizes the objective of this experiment.

\section{Scope and Objectives}

The two main objectives in the stratified flow experiment are to understand density gradient driven flow phenomena in the broken circular pipe and to provide data for the validation of computer codes such as CFD or a system analysis codes

To meet the first objective, the following characteristics of the flow phenomena which are typical to the VHTR DEGB scenario were investigated in the experiment (See Figure 2-1):

- Characteristics of gravity current in the horizontal pipe

- Characteristics of gravity current at the expansion point from the pipe to the vessel.
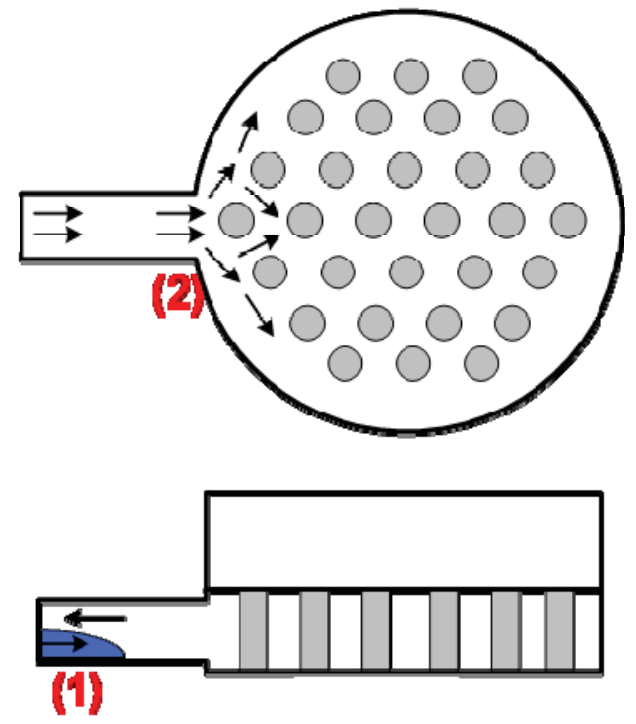

(1) Etritiled Flew In the horkental Pipo

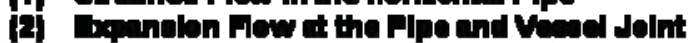

Figure 2-1. Flows of interest in the isothermal full-break experiment.

Previous research has been conducted for the gravity current flow in the civil engineering application. This gravity current flow is very similar to the air-ingress situation, but has some differences, in particular, for the channel cross-section shapes. Figure 2-2 (a) shows the channel shape in previous gravity current studies. These previous experiments were carried out by using rectangular channels. In the rectangular channel, the channel height is not changed along the horizontal axis. It indicates that the current speed will be consistent along the axis, and the flow regime in each horizontal location will be the same. This configuration visualizes 2-D flow, so the experimental results were well matched to the previous theoretical models derived in the 2-D axis. In the air-ingress condition, which consists of a circular channel, the channel height is changed along the horizontal axis (see Figure 2-2 [b]). At the center, the height is large, and at the side, the height is very small. Therefore, at the center, the current speed will vary from the speed near the sides. This might provide different flow regimes for different locations in the circular pipe. The circular pipe appears to show some 3-D effect on the gravity current flow. It is therefore necessary to see the differences of the stratified flow between a rectangular channel and a 
circular pipe. It is therefore not clear whether the previous 2-D models are still valid for the circular geometry.

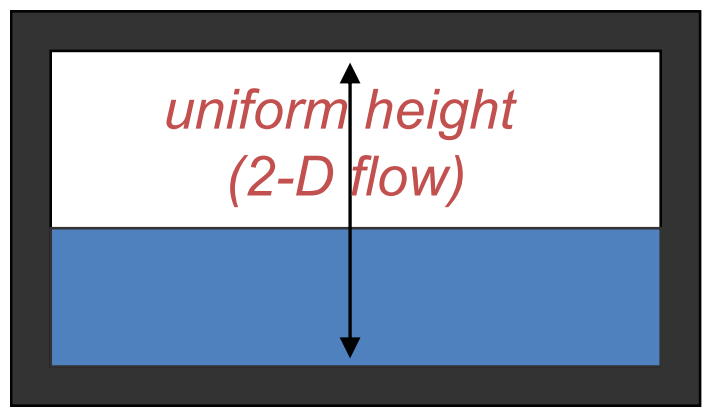

(a) Previous gravity current studies

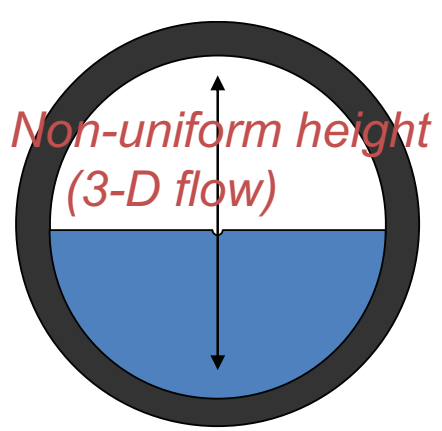

(b) VHTR air-ingress situation

Figure 2-2. Comparisons between previous gravity current studies and VHTR air-ingress condition.

\section{Experimental Set-up}

Air-ingress experiments of a gas-cooled reactor were conducted using a scaled-down test apparatus based on the General Atomics GTMHR design. The DEGB was considered to be the worst case of the air ingress accident. A pipe break accident scenario that mimics the DEGB was demonstrated by opening a pneumatic knife gate valve. The pressure and temperature were measured by transducers on each cylinder for pressure and by thermocouples for temperature measurements. Flow visualization was recorded by a video camera. The operating conditions were ambient pressure and temperature.

The experiments mimicked air ingress into a typical NGNP gas-cooled reactor lower plenum as a countercurrent air and helium flow when the inlet pipe break occurs in the hot duct. A liquid system with water, salt water, or water-sucrose was used. The liquid-liquid system data was used for validating the computational fluid dynamic models.

The DEGB isothermal experiment consists of two tanks and a horizontal pipe that connects the two tanks, as shown in Figure 2-3. Along the horizontal pipe is a sliding gate valve (Dezurik Knife Gate Valve, KCB, 8, F1, S2, TDP-EPDM*CY-PC8CS,4VG63) installed to separate the tanks. Initially, both tanks were filled with different fluids having different densities, and the valve was closed. Once the predetermined initial conditions were achieved, the experiments were started by quickly opening the valve. After the valve is open, a counter-current stratified flow formed in the test-section where the heavy fluid intrudes into the light fluid at the bottom, and the light fluid intrudes into the heavy fluids at the top. A port at the bottom of the two tanks was linked to a differential pressure transmitter to be used for setting up the initial pressure equilibrium and stabilization. Each tank also had a pressure transducer for an independent pressure monitoring. The tanks and the pipe were made of transparent acrylic for optical measurements and flow visualization. The detailed test section designs and blueprints are enclosed in the Appendix A.

Figure 2-3 shows the experimental set-up. This experiment consists of two tanks, two horizontal pipes, and a gate valve for separation of two tanks. The horizontal pipe diameter and length were designed to be $0.2 \mathrm{~m}$ and $1.0 \mathrm{~m}$, respectively. The tank diameter was $0.9 \mathrm{~m}$, and the height was $1.0 \mathrm{~m}$. Initially, the gate valve was closed, and water and brine filled the two tanks, respectively. The height of the brine and the water at the initial condition were about one-third of the full tank height $(=0.3 \mathrm{~m})$. After achieving a predetermined condition, the experiment was started by opening the gate valve with an 80 psi compressed air. The valve was pneumatically controlled by a solenoid valve. The gate opening size is the same size of the horizontal pipe to avoid flow distortion when liquid flows through the gate valve. 


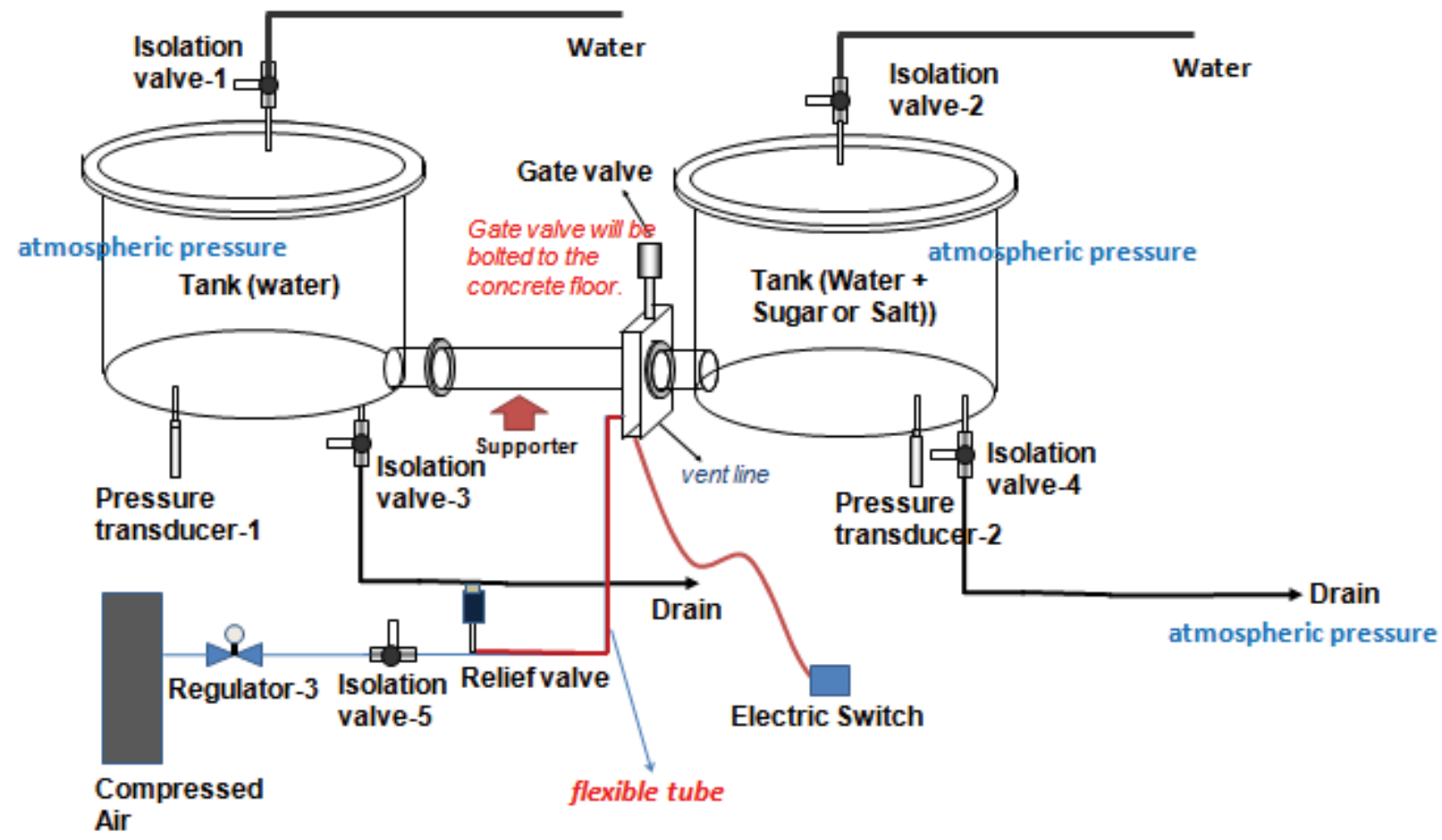

Figure 2-3. Schematics of isothermal DEGB experiment.
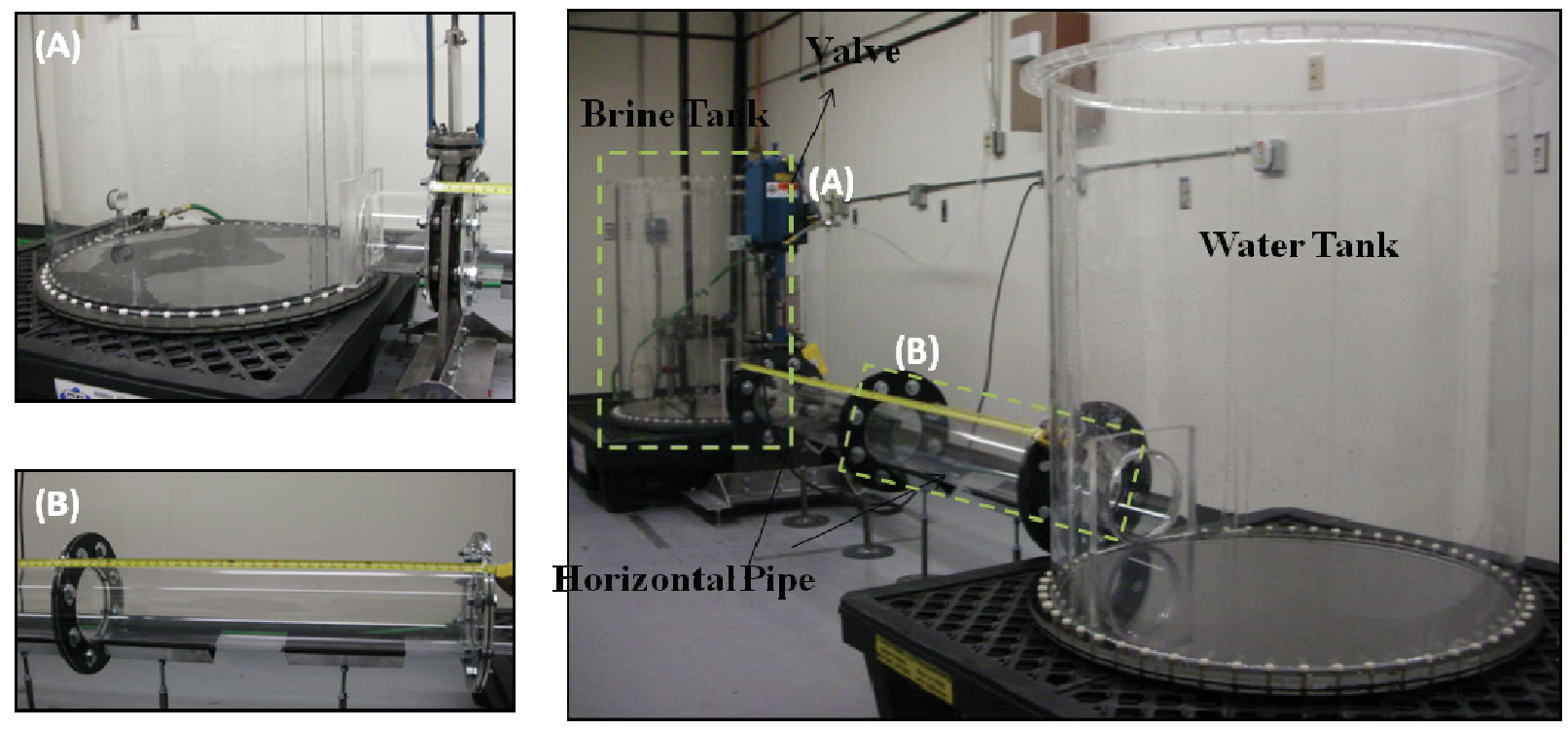

Figure 2-4. Isothermal stratified flow experimental set-up for brine-water.

Figure 2-5 shows the gate valve installed in the test section. This gate valve is actuated by compressed air. The compressed air is controlled by a solenoid valve and an electrical switch. The valve is vertically oriented and mounted on the concrete floor. Figure 2-6 shows the overall set-up of the test facility. The detailed valve-mount design and stress analysis results are described in Appendix B. 

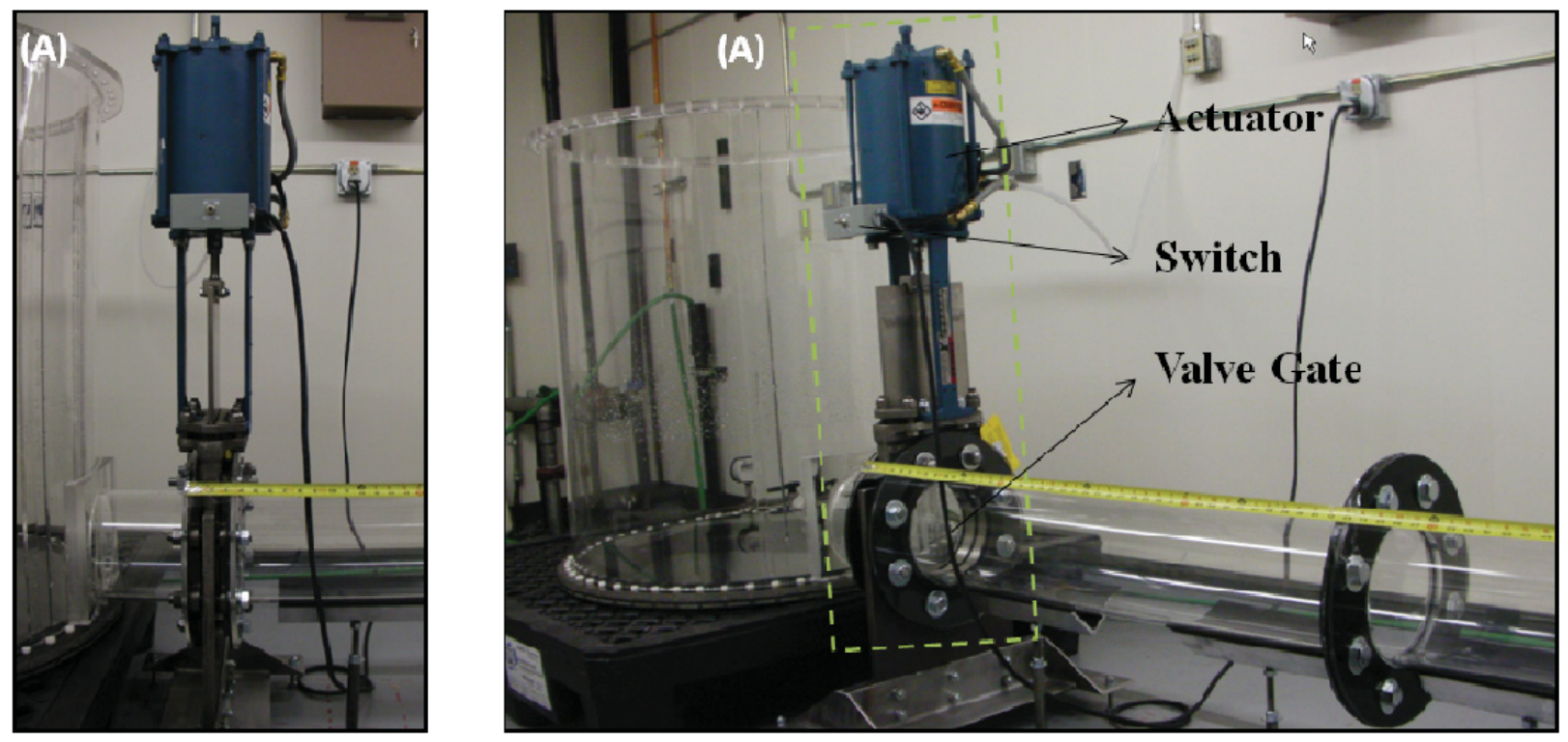

Figure 2-5. Gate valve installation.
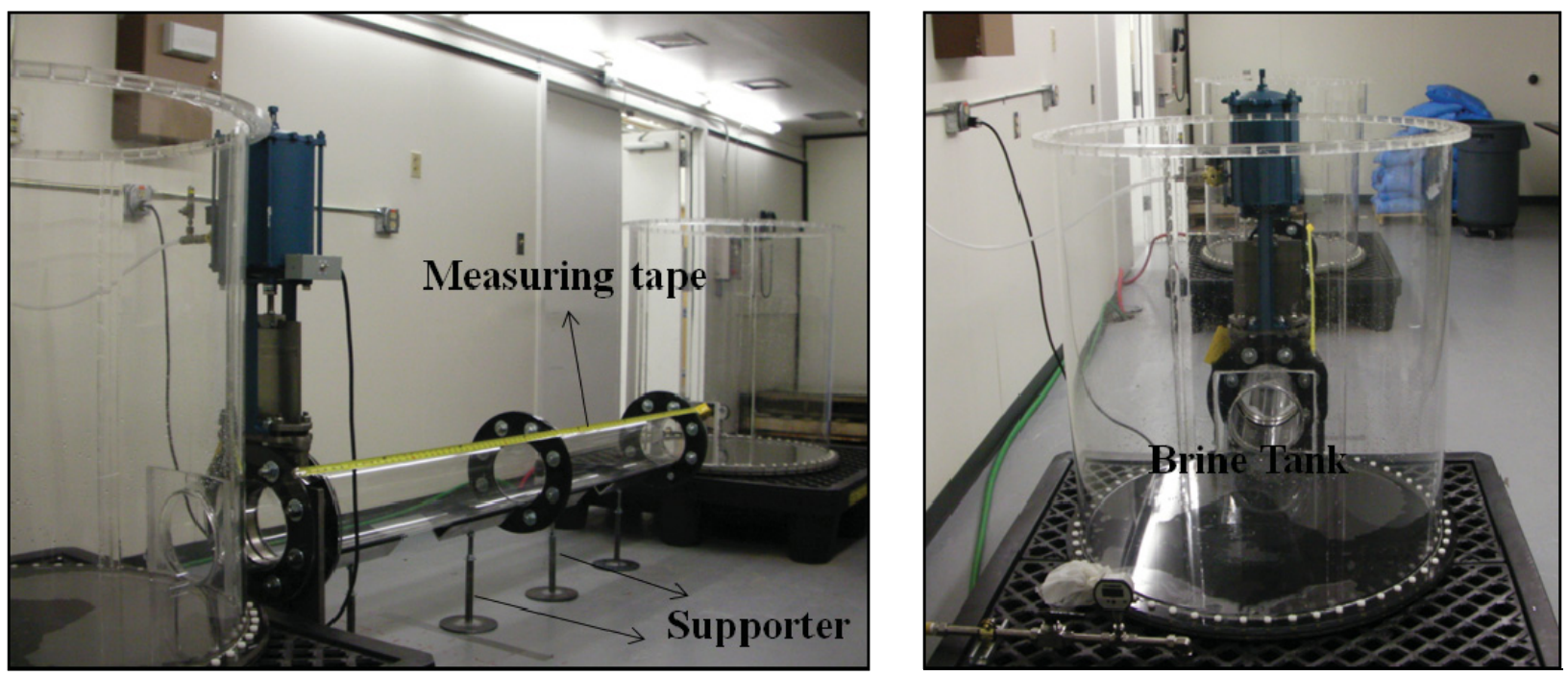

Figure 2-6. Overall set-up of isothermal experiment.

Table 2-2 shows the test matrix of this experiment. The experiment used brine and sucrose as heavy fluids, and water and air as light fluids. The density ratios are changed between 0.98 and 0.866 , except for the air/water experiment. The total number of test cases is 9, including the air and water experiment. This experiment covers Reynolds numbers from $2.3 \times 10^{4}$ to $3.79 \times 10^{5}$. Therefore, the main flow is in the turbulent flow regime, which is the same as predicted in the real air-ingress accident. In this regime, the gravity current or density gradient stratified flow is not affected by viscous effect.

Before starting the experiment, the fluid's densities (specific gravity) were measured by a hydrometer. Later, the brine and sucrose were separately sampled for validating measurement. Figure 2-7 shows the brine and sucrose samples taken in a small bottle. In each sample, fluid types and measuring date were written on the bottle surface. 
Table 2-2. Experimental conditions and case summary.

\begin{tabular}{|lccccc|}
\hline & Heavy Fluid & Light Fluid & $\begin{array}{c}\text { Heavy Fluid } \\
\text { Density }\left(\mathbf{k g} / \mathbf{m}^{\mathbf{3}}\right)\end{array}$ & $\begin{array}{c}\text { Light Fluid } \\
\text { Density }\left(\mathbf{k g} / \mathbf{m}^{\mathbf{3}}\right)\end{array}$ & Density Ratio \\
\hline Case 1 & Sugar & Water & 1020 & 1000 & 0.980 \\
Case 2 & Sugar & Water & 1025 & 1003 & 0.979 \\
Case 3 & Salt & Water & 1045 & 1002 & 0.959 \\
Case 4 & Sugar & Water & 1061 & 1002 & 0.944 \\
Case 5 & Sugar & Water & 1080 & 1002 & 0.928 \\
Case 6 & Sugar & Water & 1100 & 1000 & 0.909 \\
Case 7 & Salt & Water & 1130 & 1002.5 & 0.887 \\
Case 8 & Sugar & Water & 1155 & 1000 & 0.866 \\
Case 9 & Water & Air & 1000 & 1.2 & 0.0012 \\
\hline
\end{tabular}

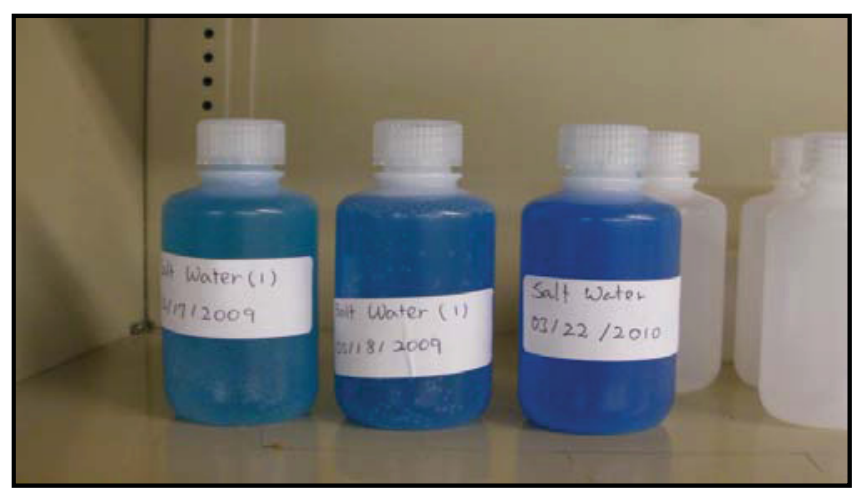

Figure 2-7. Brine and sucrose samples.

\section{Experimental Procedure}

The isothermal experimental procedure is as follows:

1. The knife gate valve, isolation valves 3 and 4 are closed (See Figure 2-3).

2. Water is added to each tank through a water feed line.

3. Salt (or sugar) and a $100 \mathrm{ppm}$ concentration of dye (indigo type blue dye, certified by International to the American National Standards Institute/National Science Foundation Standard 60 for use in drinking water) are added to a tank, the brine is stirred for mixing, and a $10 \mathrm{~mL}$ brine sample is taken for a density measurement.

4. Isolation Valve-5 is opened, and the pneumatic knife gate valve is opened by turning the switch on.

5. The flow pattern is observed in the horizontal pipe.

6. The flow is recorded using a video camera.

7. After the experiment, the power source to the knife gate valve is de-energized.

8. Isolation valves 3 and 4 are opened to discharge water to sewage. The sewage drain is located in the floor of Room E. 


\section{Measurement}

This experiment measured two parameters for characterizing stratified flow: current velocity and current depth. To measure those parameters, two digital video cameras (30 frames per second) were used. One, installed on the top of the horizontal pipe, measured the time when the current front passes through pre-marked positions. Since the marking positions are known, the current speed can be calculated by measuring time. To measure the current depth, the other camera was installed at the side of the horizontal pipe. The analysis was conducted by an image-processing software. The measured data are compared with the CFD simulations and the theoretical models.

\section{Experimental Results and Discussions}

Figure 2-8 shows the heavy-fluid current propagation through the horizontal pipe for Case 8 (watersucrose, density ratio $=0.866$ ). In this case, the heavy-fluid was sucrose, and the light-fluid was water. The density ratio was 0.866 , which means that the sucrose is about $13.4 \%$ heavier than the water. As shown in Figure 2-8, the current rapidly propagates through the pipe, occupying about one-half of the pipe diameter. This result is consistent with the previous observations reported for the lock exchange flow in the Boussinesq flow regimes. In Case 8 , the heavy current travelling speed was estimated to be $\sim 0.26 \mathrm{~m} / \mathrm{s}$. 

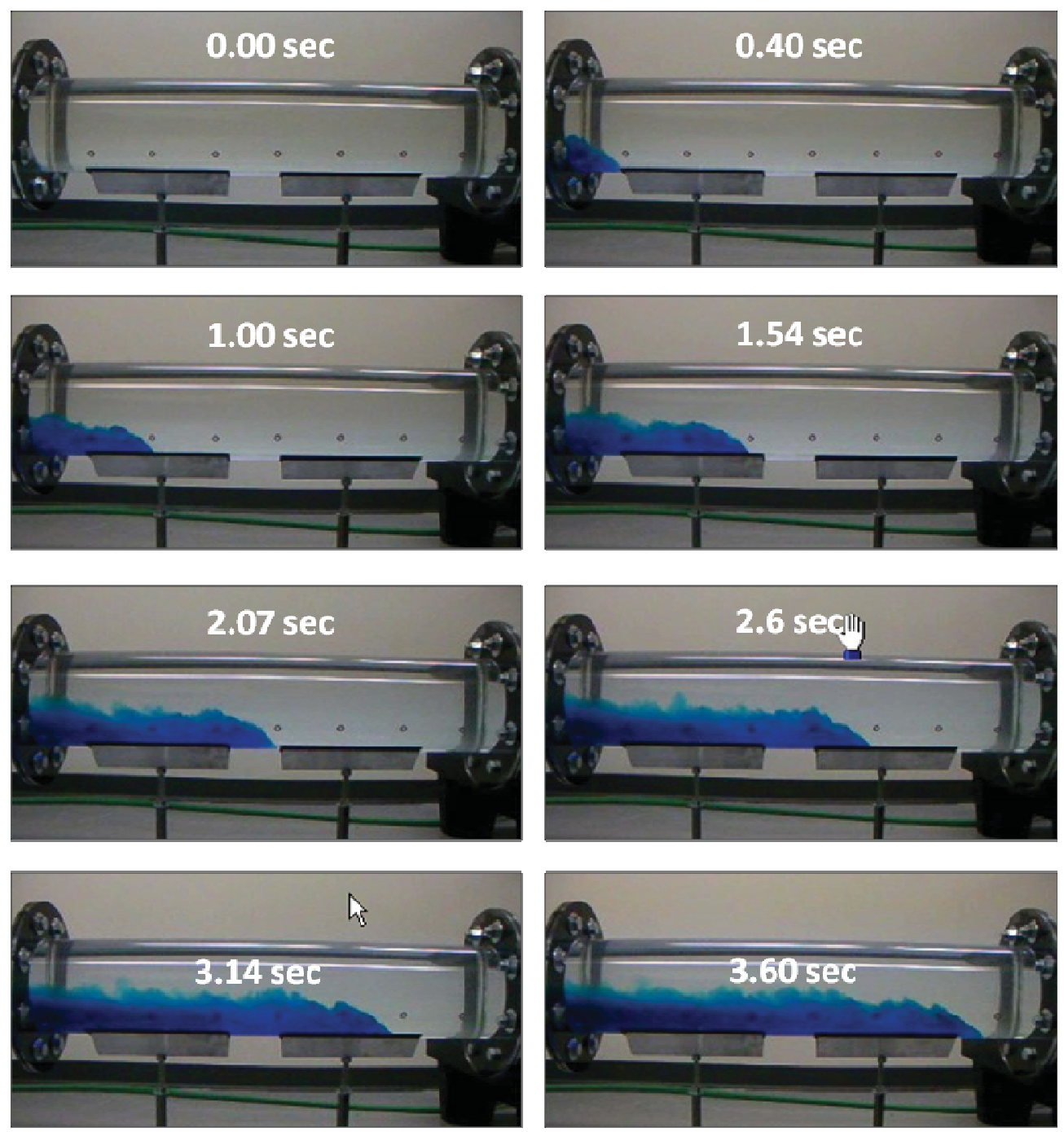

Figure 2-8. Progress of gravity current and stratified flow (water-sucrose, density ratio $=0.866($ Case 8$)$ ).

The experimental results are summarized in Table 2-3 and Figure 2-9. The first column in Table 2-3 represents the traveling distance, which was determined by measuring marking spots. The columns from the second to the end show the traveling time when the current arrived at the marking spots. Figure 2-9 plots these data. As shown, the traveling distance has a linear relationship with the traveling time. It means that the heavy current speed is constant throughout the axial direction of the horizontal pipe. This is because of the high Reynolds numbers of the gravity current. For high Reynolds numbers, inertia force dominates viscous effects, so the flow can be considered as an inviscid flow, indicating that the frictional loss can be ignored. The current speed can be calculated by an inverse of the slope of each dataset. As shown in the figure, the current speed is significantly affected by density ratios. The lowest density ratio is 0.866 and the largest is 0.98 for the liquid-liquid experiment. The velocity difference between these two cases are about a factor of $2.5\left(\mathrm{~V}_{\mathrm{r}=0.866}=0.254 \mathrm{~m} / \mathrm{s}\right.$, and $\left.\mathrm{V}_{\mathrm{r}=0.98}=0.101 \mathrm{~m} / \mathrm{s}\right)$. If the density ratio is small (the density differences are large), the current speed is fast because of the larger density gradient. The current speed $(\mathrm{V}=1.69 \mathrm{~m} / \mathrm{s})$ for the air-water experiment was estimated to be even an order faster than for the liquid-liquid experiment. 
Table 2-3. Experimental results (traveling distance $[\mathrm{x}]$ vs. time).

\begin{tabular}{|l|c|c|c|c|c|c|c|c|c|}
\hline $\mathbf{x}(\mathbf{m})$ & $\begin{array}{c}\text { Case 1 } \\
\text { time (s) }\end{array}$ & $\begin{array}{c}\text { Case 2 } \\
\text { time (s) }\end{array}$ & $\begin{array}{c}\text { Case 3 } \\
\text { time (s) }\end{array}$ & $\begin{array}{c}\text { Case 4 } \\
\text { time (s) }\end{array}$ & $\begin{array}{c}\text { Case 5 } \\
\text { time (s) }\end{array}$ & $\begin{array}{c}\text { Case 6 } \\
\text { time (s) }\end{array}$ & $\begin{array}{c}\text { Case 7 } \\
\text { time (s) }\end{array}$ & $\begin{array}{c}\text { Case 8 } \\
\text { time (s) }\end{array}$ & $\begin{array}{c}\text { Case 9 } \\
\text { time (s) }\end{array}$ \\
\hline 0 & 0 & 0 & 0 & 0 & 0 & 0 & 0 & 0 & 0 \\
\hline 0.127 & 1.54 & 1.13 & 0.67 & 0.73 & 0.53 & 0.47 & 0.5 & 0.4 & - \\
\hline 0.254 & 3.2 & 2.3 & 1.6 & 1.47 & 1.26 & 1 & 1.2 & 1 & - \\
\hline 0.381 & 4.54 & 3.6 & 2.54 & 2.2 & 2.06 & 1.54 & 1.8 & 1.54 & - \\
\hline 0.508 & 5.6 & 4.9 & 3.6 & 2.93 & 2.66 & 2.07 & 2.47 & 2.07 & - \\
\hline 0.635 & 6.74 & 5.8 & 4.87 & 3.8 & 3.33 & 2.6 & 3.07 & 2.6 & - \\
\hline 0.762 & 8 & 7 & 5.94 & 4.6 & 4 & 3.14 & 3.6 & 3.14 & - \\
\hline 0.889 & 9.14 & 8 & 6.94 & 5.4 & 4.66 & 3.74 & 4.14 & 3.6 & - \\
\hline 1.016 & 10.07 & 8.87 & 7.67 & 6.13 & 5.13 & 4.14 & 4.54 & 4 & 0.6 \\
\hline
\end{tabular}

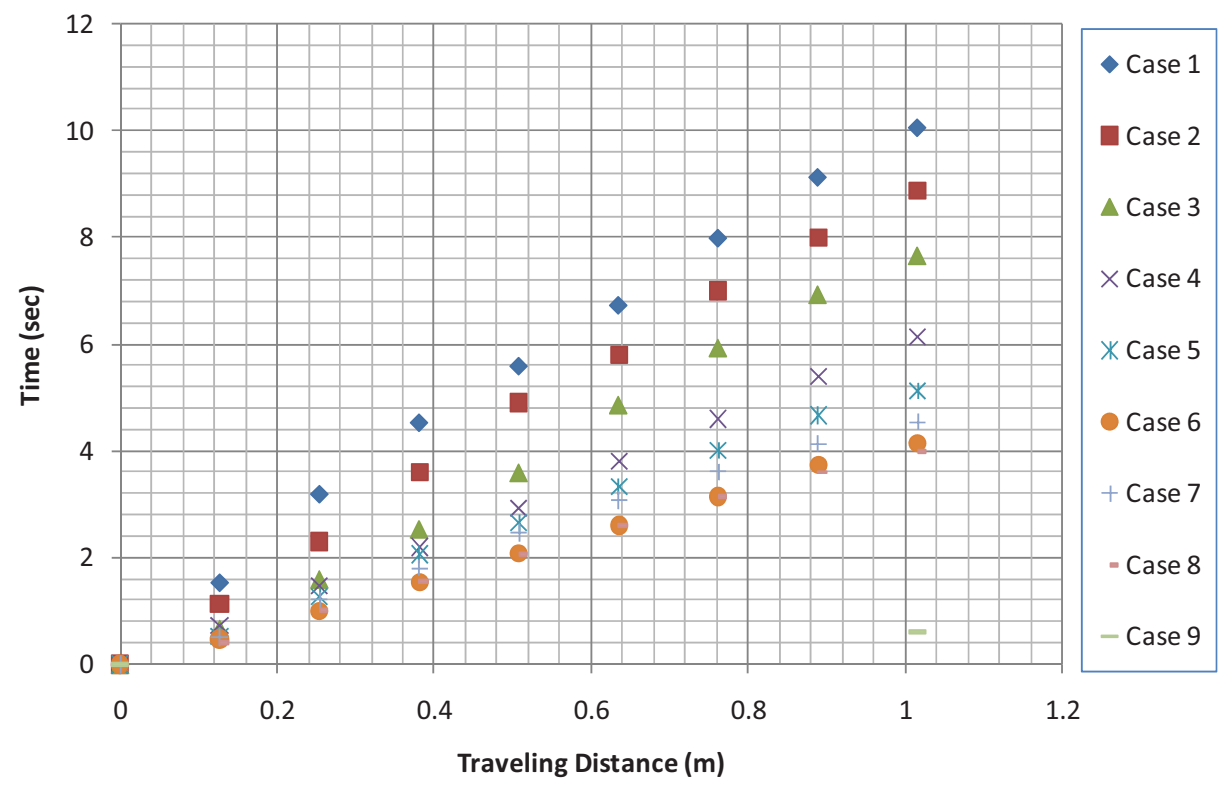

Figure 2-9. Experimental results (traveling distance vs. time).

Table 2-4 summarizes the estimated current speeds between the experiments and theoretical estimations. The heavy current speeds in this experiment range between 0.101 and $1.69 \mathrm{~m} / \mathrm{s}$. As shown in the table, the theoretical estimation is in good agreement with the experimental data (within $10 \%$ error) for all the cases. The comparisons between the experiment and the theoretical models are discussed in more detail in the next section.

Table 2-4. Comparisons of current speeds between experiment and Benjamin's theoretical model.

\begin{tabular}{|l|l|l|l|l|l|l|l|l|l|}
\hline Velocity $(\mathrm{m} / \mathrm{s})$ & Case 1 & \multicolumn{1}{|c|}{ Case 2 } & Case 3 & Case 4 & Case 5 & \multicolumn{1}{|c|}{ Case 6 } & \multicolumn{1}{|c|}{ Case 7 } & \multicolumn{1}{c|}{ Case 8 } & \multicolumn{1}{c|}{ Case 9 } \\
\hline Experiment & 0.1009 & 0.1155 & 0.1375 & 0.1657 & 0.1814 & 0.2241 & 0.2381 & 0.254 & 1.69 \\
\hline Theory & 0.1028 & 0.1145 & 0.146 & 0.1705 & 0.191 & 0.2127 & 0.237 & 0.26 & 1.68 \\
\hline Error $(\%)$ & 1.88 & 0.86 & 6.18 & 2.89 & 5.29 & 5.08 & 0.46 & 2.36 & 0.59 \\
\hline
\end{tabular}




\subsection{Validation of CFD Code for Stratified Flow}

Computational fluid dynamics methods for a gravity current flow were validated by analyzing CFD and comparing the results with experimental data. Details of this validation are described in this section.

\section{Preliminary CFD Result and Validation Study with Experiment}

\section{CFD Specification and Fluid Properties}

FLUENT 6.3.26 was used to understand stratified flow in small density ratio cases (from Case 1 to Case 8 in the isothermal experiment). Figure 2-10 indicates the overall geometry of the present CFD model of isothermal experiment simulations.

$<$ Overall geometry of CFD model $>$

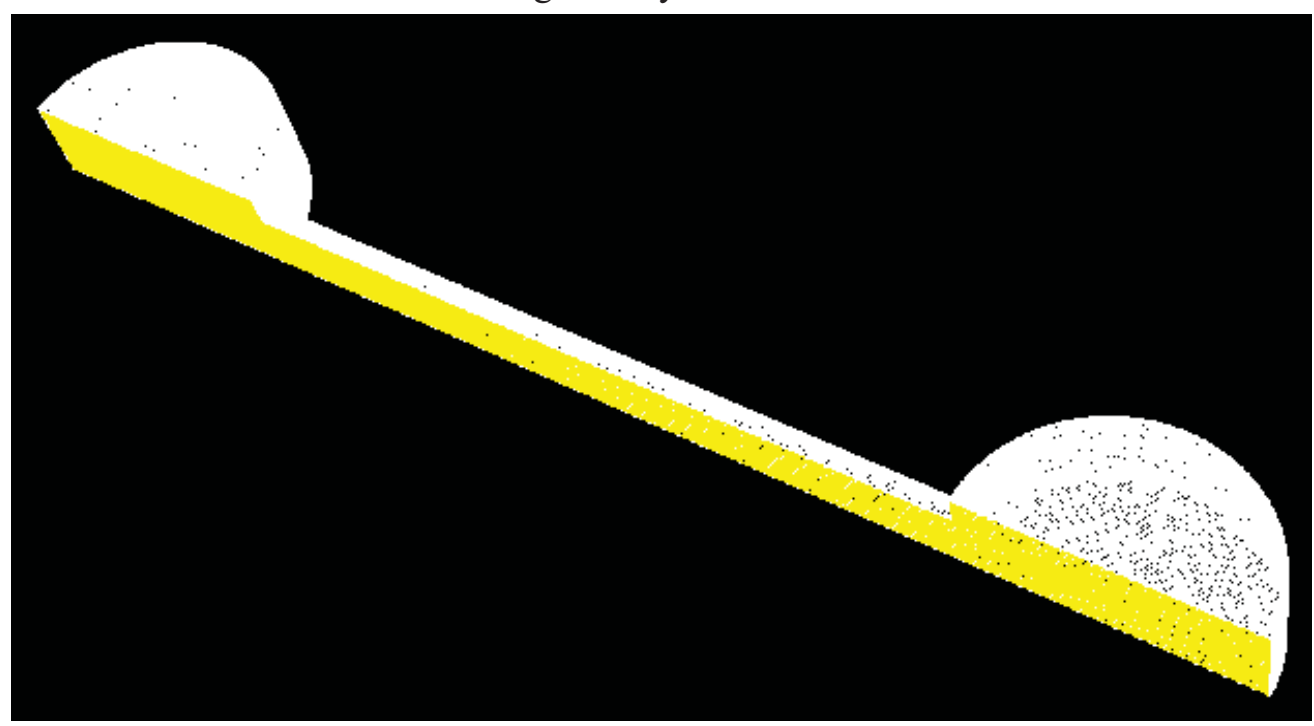

$<$ Side view of model $>$

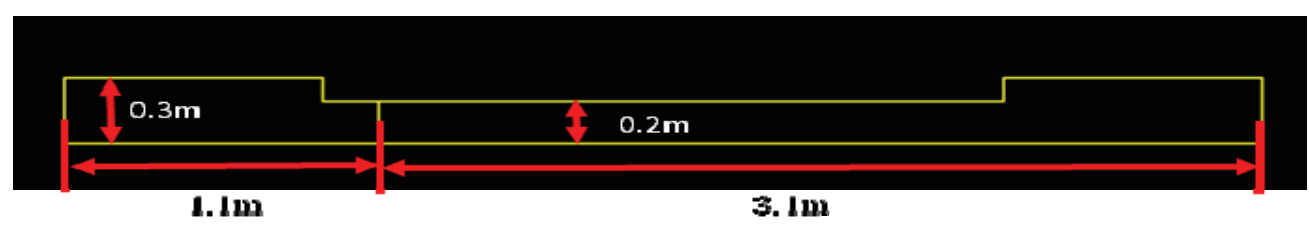

Figure 2-10

Figure 2-10. Overall geometry with normal mesh and side view from symmetry surface.

A 3-D model was developed to simulate the air-ingress phenomena using the INL experimental setup. The overall geometry of the CFD model used for the experiment consisted of three basic parts as shown in Figure 2-10: a heavy fluid brine or sucrose tank (upper left), a light fluid water or air tank (lower right), and a connecting pipe (going between the two tanks). Three different types of polyhedral meshes (coarse, normal, and fine) were generated and used for the grid sensitivity and convergence study. The first 3-D model developed used a coarse mesh with appropriate grid sizes. Rediscretization with half of coarse mesh grid spacing (normal mesh) and finer meshes were then used as part of Richardson extrapolation method. 
The Fluent specification and model used in this simulation are listed as follows:

- Solver:

- Solver: pressure based

- Formulation: implicit

- Space: 3-D double precision

- Time: unsteady

- Velocity formulation: absolute

- Gradient I option: green-gauss cell based

- Unsteady formulation: $2^{\text {nd }}-$ order implicit

- Pressurevelocity coupling: PISO

- Discretization:

- Pressure: PRESTO!

- Momentum: $2^{\text {nd }}$-order upwind

- Turbulent kinetic energy: $2^{\text {nd }}$-order upwind

- Turbulent dissipation rate: $2^{\text {nd }}$-order upwind

- $\quad$ Species: $2^{\text {nd }}$-order upwind

- Energy: $2^{\text {nd }}$-order upwind

- Viscous Model:

- Turbulence model: realizable k-e

- Wall function: standard wall function

- Energy equation

- Species transport model:

- $\quad$ Mixture material: Mixturetemplate

- 2 species: water and brine

- Species transport model:

- Mixture material: Mixturetemplate.

Figure 2-11 shows the initial condition. The left side is filled with brine water that is slightly heavier than pure water density (red: heavy fluid), and right side is filled with pure water (blue: light fluid). Therefore, as transient simulation starts, the heavy fluid intrudes into the light fluid by driving force of density-driven current, which is also defined as stratified flow. Initial conditions for temperature and pressure of both fluids were set as $300 \mathrm{~K}$ and $1 \mathrm{~atm}$. identically. 


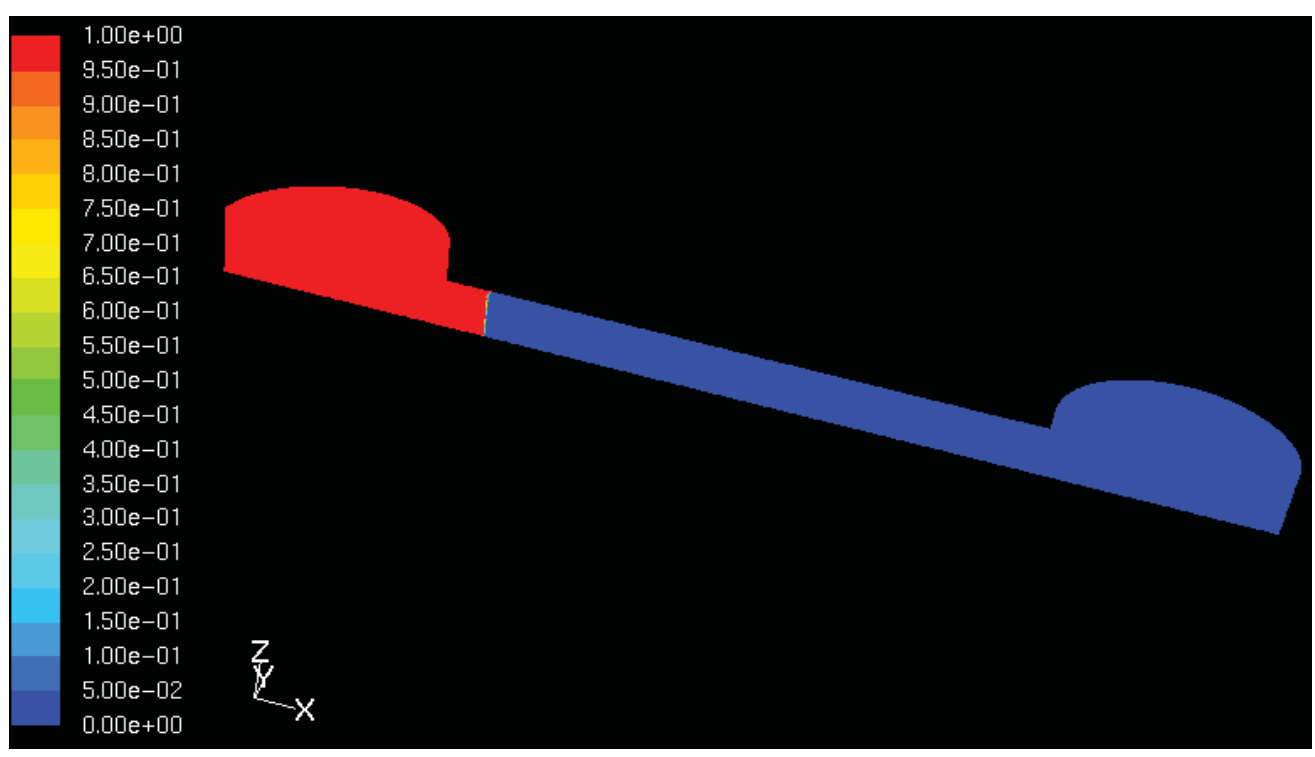

Figure 2-11. Initial brine-water mass fraction (red: brine, blue: water).

Figure 2-12 shows how brine (heavy fluid) intrudes into the water in the lower zone while water (relatively light fluid) moves forward into the brine zone by expressing contour of brine mass fraction at different times (transient simulation result). Three types of mesh (coarse, normal, and fine) were implemented for predicting appropriate front speed in this study. Those CFD simulation results observe quite constant increments of front-head position by marching time. It is basically considered that fluid intrusion speed is almost constant, which means good agreement with previous theoretical models (Benjamin's Theory, invicid flow assumption). Brine water intrusion is demonstrated in 3-D simulation results by contouring of the brine mass fraction at $\mathrm{t}=1.1,3.1$, and $5.1 \mathrm{sec}$. Constant front speed and constant fluid height were also observed in 3-D view.

The fluid conditions of isothermal experiments conducted at INL varied. In fluent simulation, four fluid properties are necessary to define fluid behavior and solve the mass, momentum, energy, and species transport equation. These are density, dynamic viscosity, specific heat, and thermal conductivity. The heavy fluids used in the experiment were made from mixing sugar or salt into pure water, so the density and viscosity of the heavy fluids in each test varied based on the amount of sugar or salt added. Densities for each test case were measured, and viscosities for each test were also calculated by the correlation between density and viscosity provided from the NIST (see Figure 2-13) fluid properties database. Those updated fluid properties (density and viscosity) for brine were implemented into fluent to capture better physical phenomena of stratified flow intrusion. 

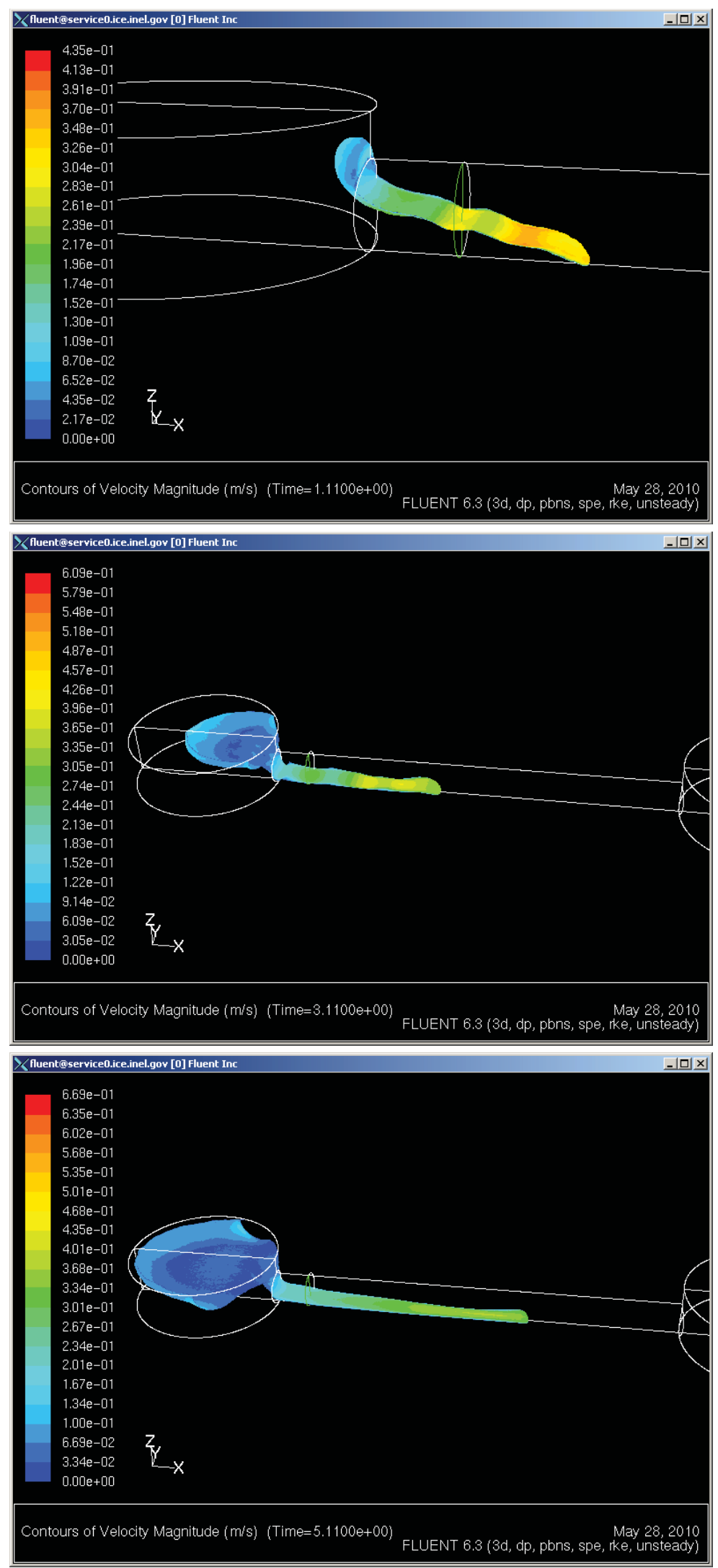

Figure 2-12. Visualization of brine water intrusion from tilted top view at marching time frame. 


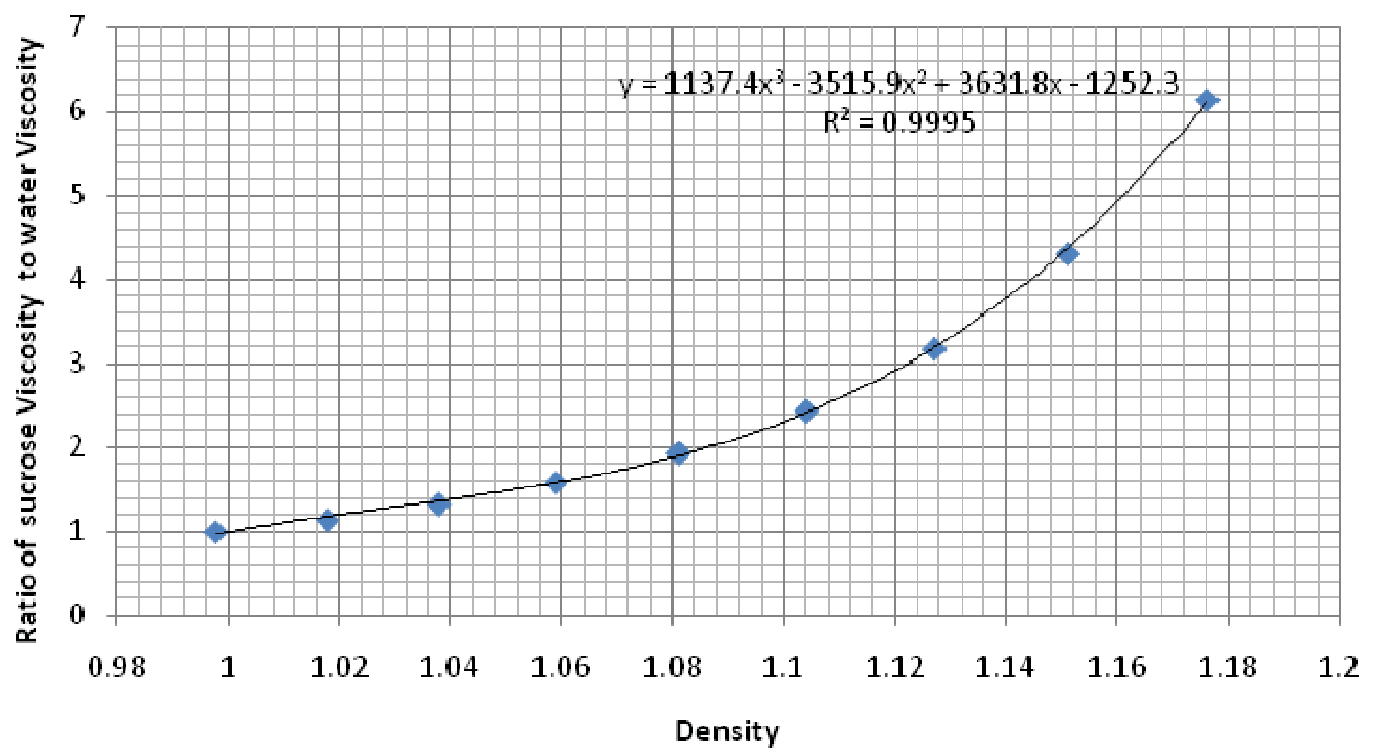

Figure 2-13. The correlation of density and ratio of sucrose viscosity to water viscosity.

\section{Grid Refinement Study}

As mentioned in the previous section, the grid refinement study was conducted for CFD validations of the spatial dimension and for better prediction of interest variable (front-head speed). The calculation method for front-head speeds in different mesh types (coarse, normal, and fine) is defined with the same method used in the experimental section. Figure 2-14, Figure 2-15, and Figure 2-16 show brine water intrudes into pure water in three mesh-type simulations. As shown in the figures, more blur interface line is observed in coarse meshes, and more sharpness and distinctive interface lines are shown in finer meshes. This sharpness affects front-head position determination, and gives accuracy on front-head speed calculation. An early propagation in Figure 2-16 shows wavy motions, which are captured for initial perturbation in finer meshes. The proper mesh quality provides a more reliable CFD calculation as well as validation. However, the finer mesh requires more computing time. In this section, eight experiment measurement data (from Case 1 to Case 8) are compared with the CFD calculation using the asymptotic approach. It is expected the computing cost will be very high. A solution that avoids this problem is discussed in the next section.

The locations of front heads were determined in this experiment by observing a video clip taken downstream of the current flow, front head, and some billows. So, the front-head positions in simulations were also calculated by the brine water mass fraction at the bottom of pipe channel. Figure 2-17 shows that the mass fraction of brine ranges from 0 to 1 . The front head speed was estimated using the distance from one position to others in the travel timing, which is superimposed on the front head ( 0.5 brine mass fraction in Figure 2-17). 

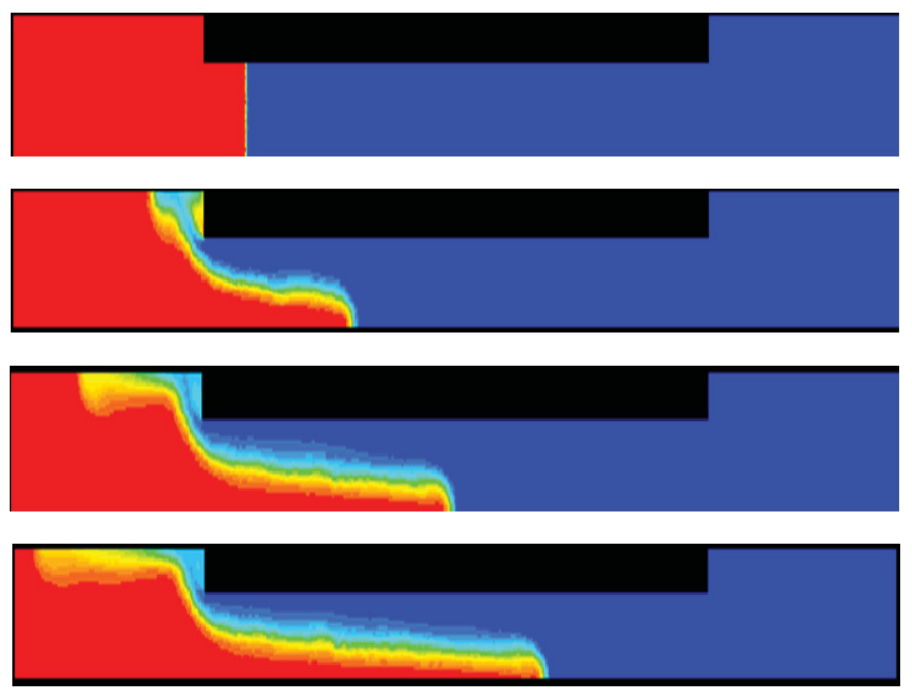

Figure 2-14. Brine intrusion simulation with coarse mesh.
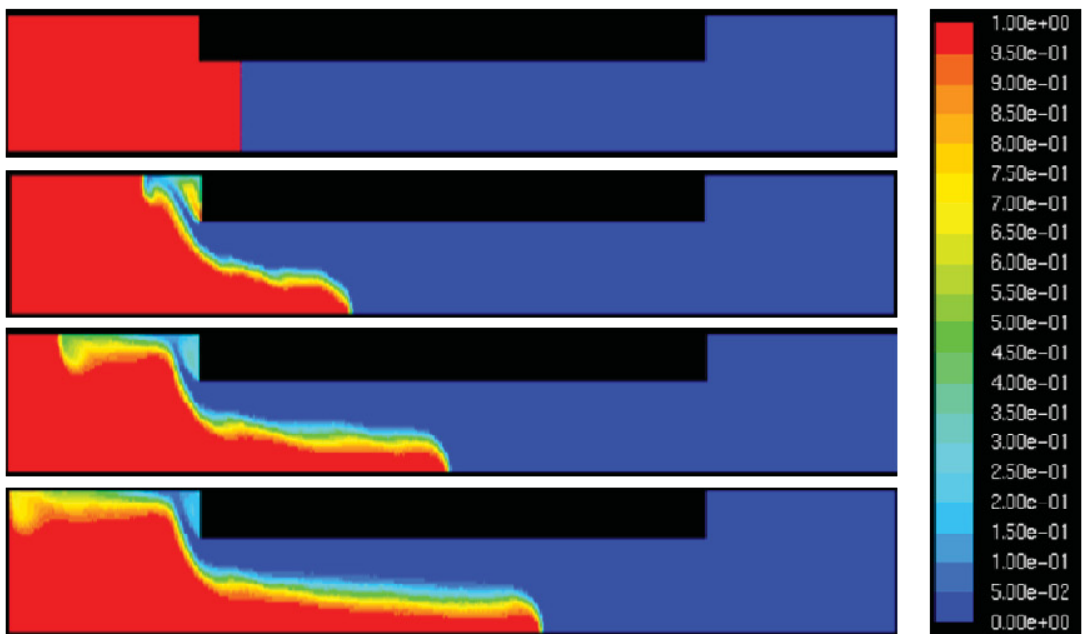

Figure 2-15. Brine intrusion simulation with normal mesh.
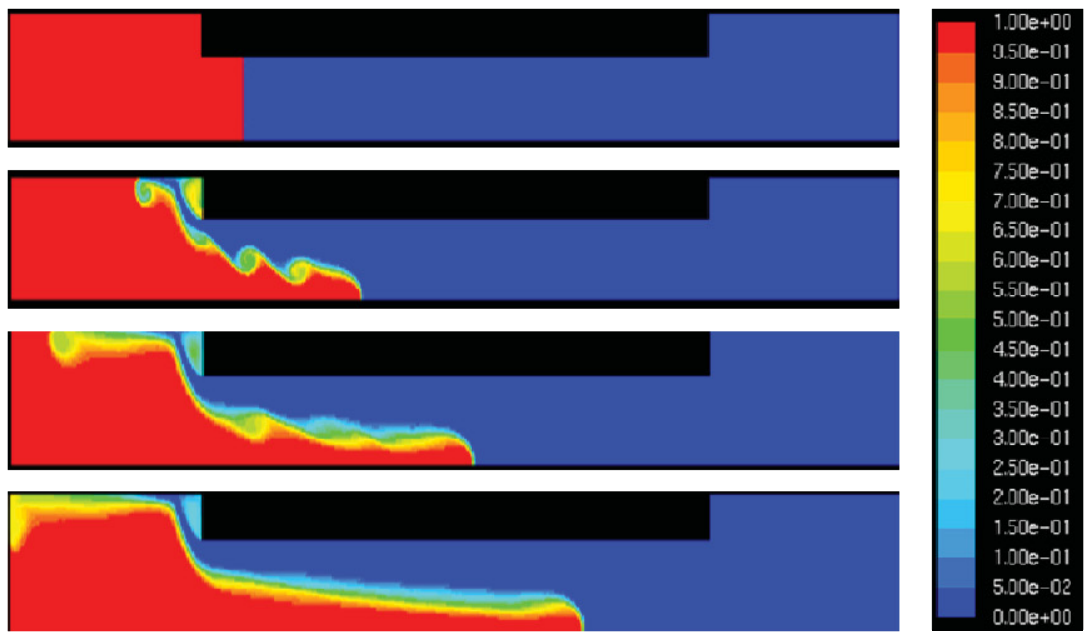

Figure 2-16. Brine intrusion simulation with fine mesh. 


\section{Brine mass fraction at the bottom of pipe (Normal mesh)}

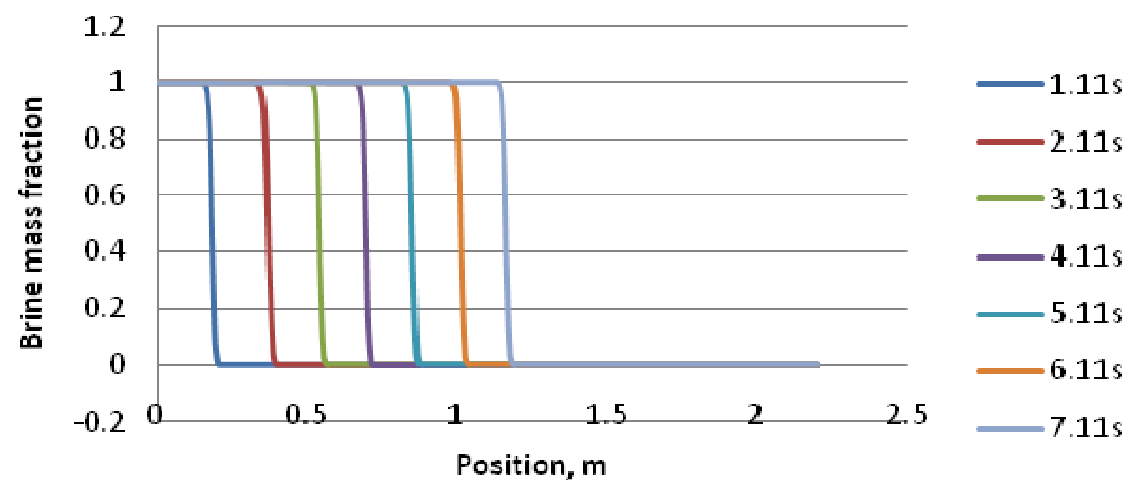

\section{Brine mass fraction at the bottom of pipe (coarse mesh)}

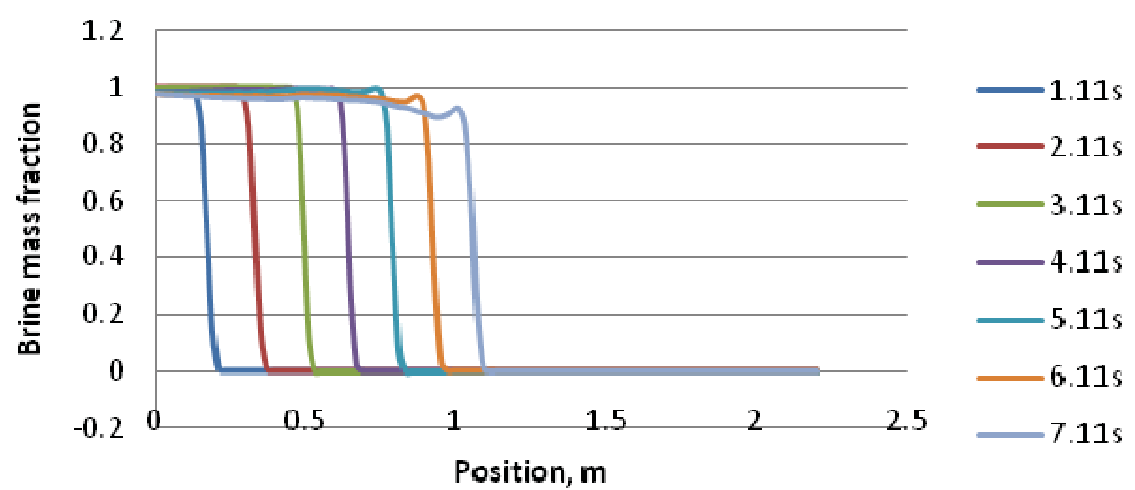

Figure 2-17. Brine mass fraction at the bottom as time marches until $7 \mathrm{sec}$ (normal, coarse mesh)

Normal mesh was found to have better distinctive interface between brine and water compared to coarse mesh. From Figure 2-17, using normal mesh, the edges of the brine or head of the intrusion fluid is well defined, and it is easy to determine half of the brine mass fraction because of this sharp interface. The accumulated numerical diffusion in normal mesh is considered smaller than the accumulated numerical diffusion in coarse mesh, which leads to better sharpening of the interface at normal mesh. It is also observed that more blurriness and less sharpening are found at the edge interface in the small density-difference case because the density-driven driving force is degraded by smaller density differences. Figure 2-18 compares the calculated intrusion-front speeds for three different mesh qualities. As shown, the calculated intrusion-front speed varies by mesh types. In order to have different mesh types, a coarse mesh is first defined with appropriate grid size, rediscretization is performed with half of the coarse mesh gird spacing (normal mesh), and fine mesh is generated out of normal by conducting rediscretization. The ratio of total cell number of normal (fine) mesh to that of coarse (normal) mesh is not exactly eight because the CFD model is a full 3-D unstructured grid. It is, therefore, more appropriate to use normalized grid spacing for a refinement study in the unstructured grid case. 


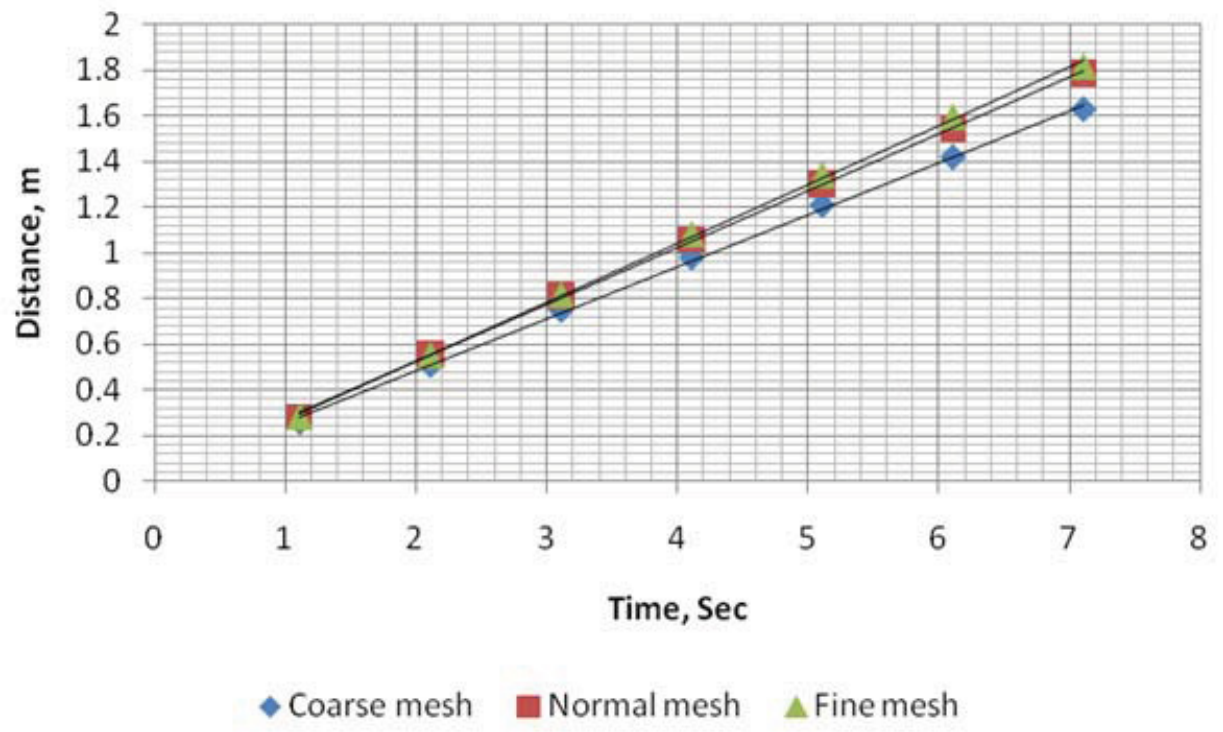

Figure 2-18. Front speed calculation in different mesh (coarse, normal, and fine).

With grid triplet (set of fine mesh, normal mesh, and coarse mesh) solutions, the unknown variables A, B, and p ought to be obtained from simple algebra as shown in Figure 2-19 where $\mathrm{p}$ is the order of convergence in the Richardson extrapolation curve, and A is the predicted value of CFD simulation result at asymptotic zero spacing grid. With constant $\mathrm{p}$ value, two solutions from normal grid and coarse grid allow the A value (Asymptotic front heat speed) to be calculated as:

$p=\frac{\ln \left(\frac{y_{3}-y_{2}}{y_{2}-y_{1}}\right)}{\ln \frac{x_{2}}{x_{1}}}$

$y=A+B x^{p}, p,\left(x_{2}, y_{2}\right),\left(x_{3}, y_{3}\right)$ are known

$\ln (y-A)=\ln (B)+p \ln (x)$

$\ln \left(\frac{y_{2}-A}{y_{3}-A}\right)=\ln \left(\frac{x_{2}}{x_{3}}\right)^{p}$

$A=\frac{0.5^{p} \times y_{3}-y_{2}}{0.5^{p}-1}, \frac{x_{2}}{x_{3}}=0.5$

where $\mathrm{p}=$ order of convergence, $\mathrm{y} 1=$ front heat speed in coarse grid, $\mathrm{y} 2=$ front head speed in normal grid, $\mathrm{y} 3$ = front head speed in coarse grid, and $\mathrm{x}=$ normalized grid spacing. If $\mathrm{p}$ is greater than unity, it converges while $\mathrm{p}$ values less than unity make the solution diverge.

The uncertainty of CFD prediction is also performed based on the Grid Convergence Index (GCI). GCI-23 is calculated instead of GCI-12 because the normal and coarse mesh solutions are utilized for the Richardson extrapolation method.

Table 2-5 summarizes front-head speed in different a grid type and normalized spacing. Each solution is properly converged with $10^{-4}$ of convergence criteria (continuity, momentums, energy, and species). It is seen that front-head speed increases as the mesh gets finer and as normalized spacing is reduced. The objective of this CFD calculation is to validate the experiment using the front-head speed calculation. It is 
therefore necessary to achieve the best prediction with less numerical error either in a spatial or temporal dimension. The Richardson extrapolation method is a well known method to validate the CFD result and give asymptotic value at zero spacing (Roche 1998).

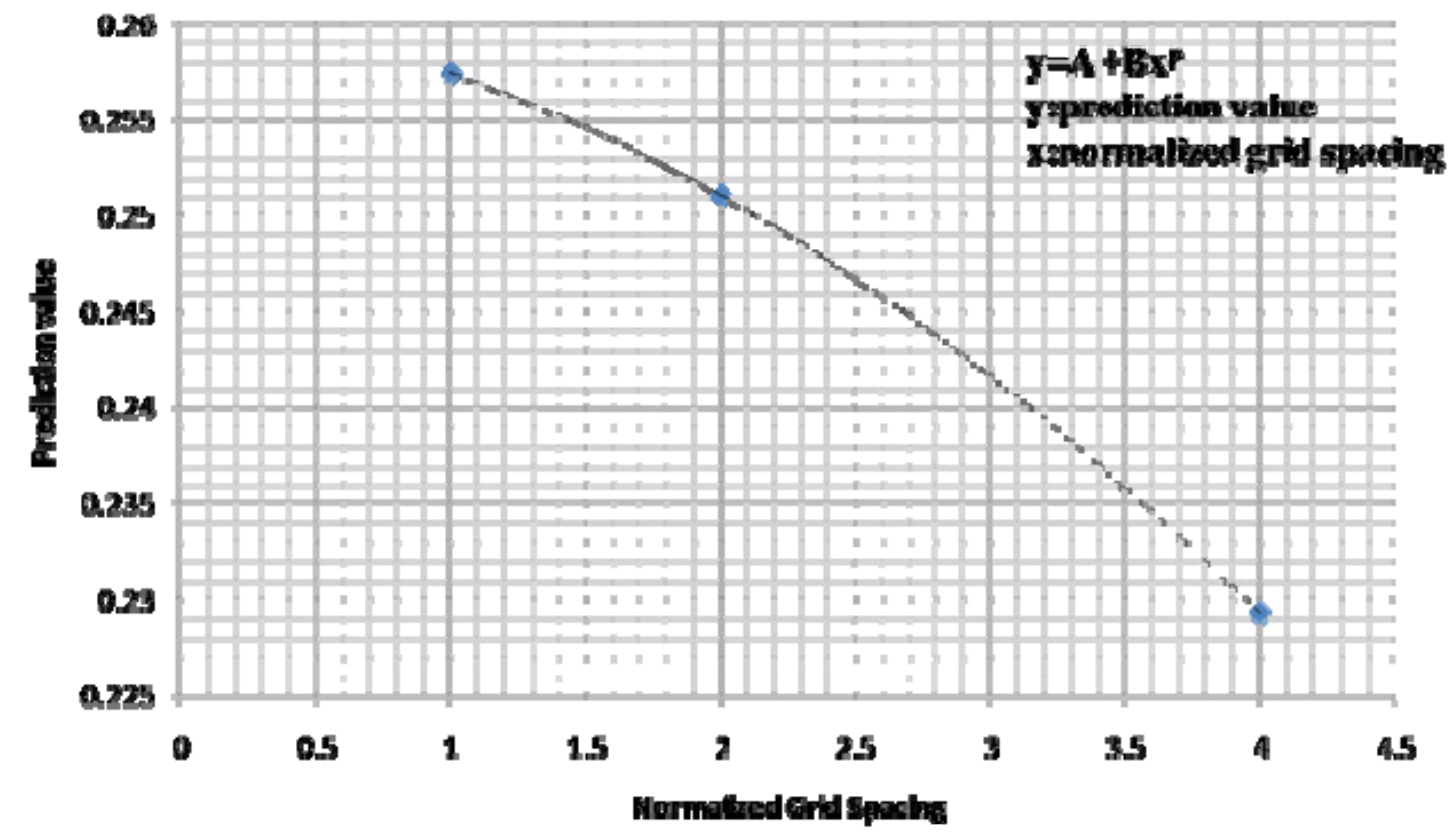

Figure 2-19. Correlation of grid spacing and prediction value in grid convergence study.

Table 2-5. Front head speed calculation at different normalized spacing

\begin{tabular}{|lcc|}
\hline \multicolumn{1}{|c}{ Grid type } & Normalized Spacing & Front Head Speed \\
\hline Fine & 1 & $0.257 \mathrm{~m} / \mathrm{s}$ \\
Normal & 2 & $0.251 \mathrm{~m} / \mathrm{s}$ \\
Coarse & 4 & $0.229 \mathrm{~m} / \mathrm{s}$ \\
\hline
\end{tabular}

From Equations 2-1 to 2-5 above, the order of convergence is calculated as

$p=\frac{\ln \left(\frac{0.229-0.251}{0.251-0.257}\right)}{\ln 2}=1.78$

Applying the Richardson extrapolation with two meshes (normal, fine), the asymptotic front head speed at zero grid spacing is calculated as

asymptotic front head speed $=0.257+\frac{(0.257-0.251)}{2^{1.78}-1}=0.260 \mathrm{~m} / \mathrm{s}$

The GCI provides an error band on the each grid type. The factor of safety is recommended to be $\mathrm{Fs}_{\mathrm{s}}=1.25$ for comparisons over three grids. The GCI for a fine grid (GCI-12) and normal grid (GCI-23) is

$G C I 12=\frac{1.25\left(\frac{0.257-0.251}{0.257}\right)}{\left(2^{1.78}-1\right)} * 100=1.26 \%$

Same approach applies for GCI-23 as

$G C I 23=\frac{1.25\left(\frac{0.251-0.229}{0.229}\right)}{\left(2^{1.78}-1\right)} * 100=4.45 \%$ 
Checking that the solutions were in the asymptotic range of convergence, is accomplished by

$\frac{4.45}{2^{1.78} * 1.26}=1.025$

which is approximately one, indicating that the solution is well within the asymptotic range of convergence. Figure 2-20 shows the estimated front-head speed $(\mathrm{m} / \mathrm{s})$ at the zero spacing with the course, normal, and fine mesh results.

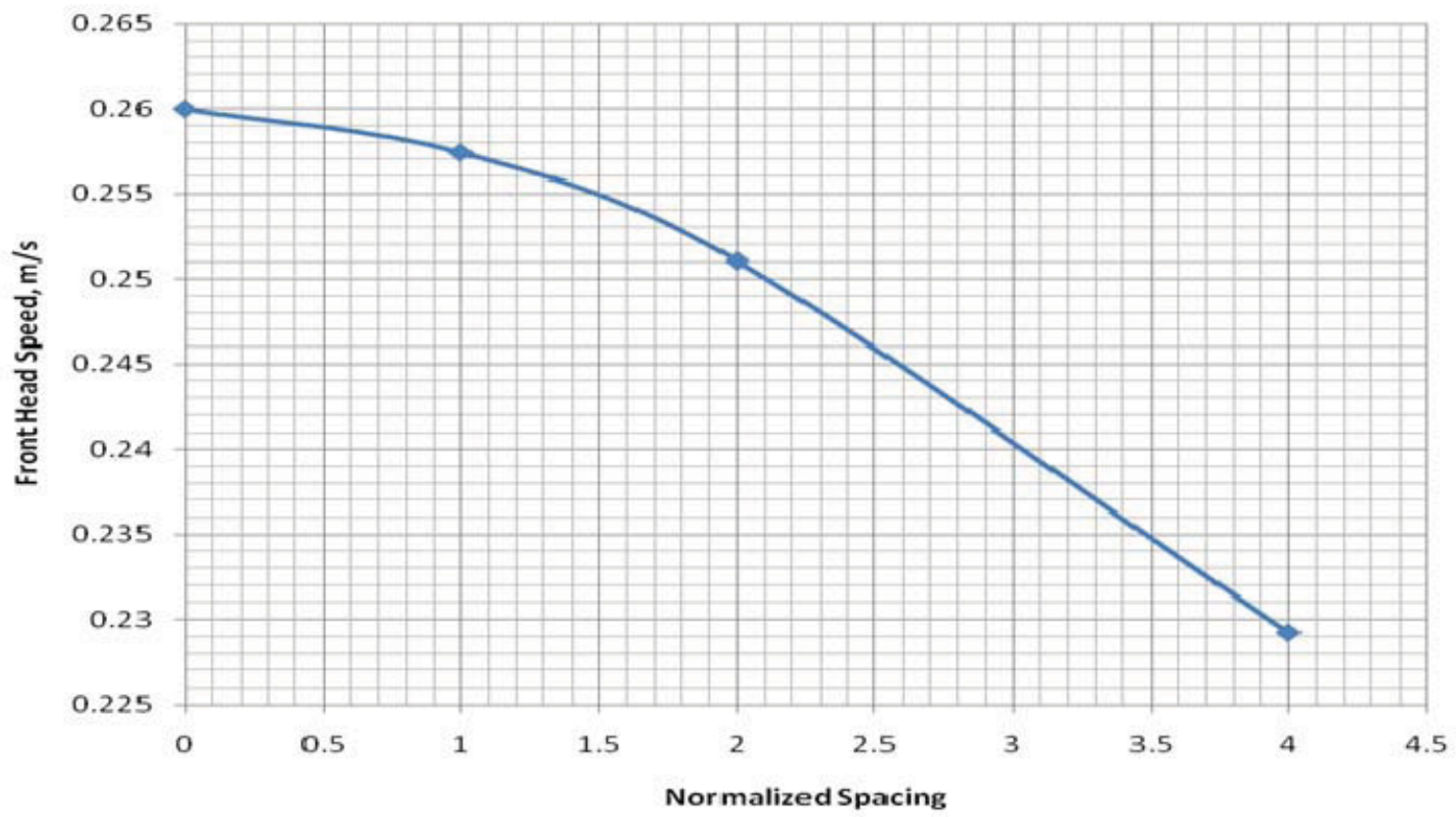

Figure 2-20. Simulated front-head speed and calculated front-head speed at zero grid spacing with order of convergence, $\mathrm{p}=1.71$ (Case 8).

Based on the CFD calculation, the front-head speed in density-driven brine-water stratified flow is estimated to be $\mathrm{V}=0.26 \mathrm{~m} / \mathrm{s}$, with an error band of $1.26 \%$ for GCI-12 and $4.45 \%$ for GCI-23. In the actual measured front-head speed of the experiment conducted for this case (Case 8), the identical condition with CFD was $0.254 \mathrm{~m} / \mathrm{s}$. Therefore, the CFD result with the asymptotic approach (Richardson extrapolation) is quite reliable for validating experiment data.

Validating the CFD front-head speed prediction by comparing FLUENT calculation with INL isothermal experimental data (as described in the previous section), INL conducted eight sets of isothermal stratified flow tests for liquid-to-liquid having different fluid densities. Heavy liquid density varies from 1.020 to $1.155 \mathrm{~kg} / \mathrm{m}^{3}$. One significant driving force of stratified flow is density difference different densities of brine water with pure water generate different current speeds. Figure 2-9 and Table 2-4 summarize the current speeds of heavy fluids.

The previous subsection showed three sets of FLUENT calculations with coarse, normal, and fine meshes to determine asymptotic front-head speed. Although these three sets of different grid size models provide a good way to calculate asymptotic front-head speed, it requires tremendous computing time to validate each case, especially the fine mesh model, which consumes more than 72 hours of computing time for 20 seconds of transient simulation. Computing time versus accuracy is a key issue in that is well understood in validating CFDs. However, in this experiment, the overall flow behavior was consistent with different fluid properties, which provided good accuracy with reduced computing time. It was assumed that the order of convergence value, $p$ (see Equation 2-1) is fully independent with each 
experimental test case because fluid properties have a very small range of variance. In addition, an INL isothermal test is being conducted with a very small density-different case calculated as $\gamma \sim 1, \gamma=$ density ratio of the low density to the heavy density, which induces relatively slow stratified flow current in the channel.

Figure 2-21 compares front-head speed prediction by CFD calculation with the asymptotic approach and experiment measurement in which the CFD prediction indicates good agreement with experiment data qualitatively. In order to perform validation procedure between code prediction and experiment data, however, it is necessary to take an uncertainty concept into consideration for both the CFD code and experiment.

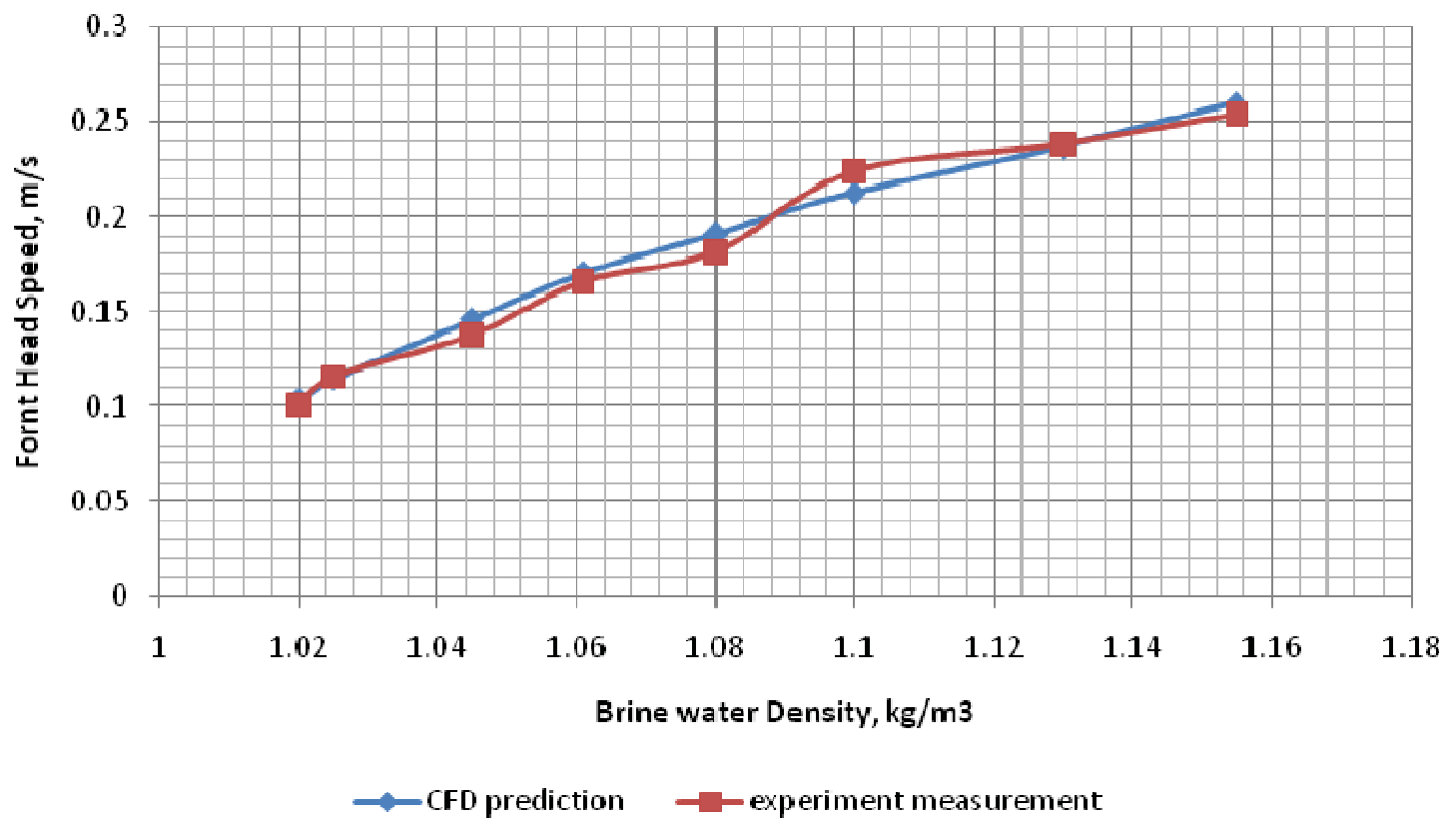

Figure 2-21. Comparison of CFD result and experiment measurement of front head speed

The linearized approximation uncertainty method (Kline and McClintonck, 1953) was used to evaluate the uncertainty of front head velocity with two measured quantities $(\mathrm{x}, \mathrm{t})$ as shown in the following mathematical procedure:

$\mathrm{V}=\frac{\mathrm{x}}{\mathrm{t}}$

$(\mathrm{dV})^{2} \approx\left[\frac{\partial}{\partial \mathrm{x}}\left(\frac{\mathrm{x}}{\mathrm{t}}\right)\right]^{2}(\mathrm{dx})^{2}+\left[\frac{\partial}{\partial \mathrm{t}}\left(\frac{\mathrm{x}}{\mathrm{t}}\right)\right]^{2}(\mathrm{dt})^{2}$

$d V=\sqrt{\left[\frac{\partial}{\partial x}\left(\frac{x}{t}\right)\right]^{2}(d x)^{2}+\left[\frac{\partial}{\partial t}\left(\frac{x}{t}\right)\right]^{2}(d t)^{2}}=\sqrt{\left[\left(\frac{1}{t}\right)\right]^{2}(d x)^{2}+\left[\left(\frac{-x}{t}\right)\right]^{2}(d t)^{2}}$

This method allows for calculating the uncertainty of measured front-head speed from both local and global points of view. Usually, local uncertainty from two local data points is relatively smaller than global uncertainty (with starting-point data and ending-point data). In this case, uncertainty in the distance between the start and end region is larger than that of the local region. Both cases of uncertainty were therefore calculated to obtain the mean value of experiment uncertainty for the front head speed. The uncertainties of front-head speed were also predicted for the CFD code using the asymptotic approach of the Richardson extrapolation method and GCI uncertainty error band. The uncertainties of front-head speed in the experiment and CFD code are tabulated in Table 2-6. 
Table 2-6. Uncertainty of front-head speeds from liquid/liquid experiments and CFD code calculations.

\begin{tabular}{|l|c|c|c|c|c|c|c|c|}
\hline & Case 1 & Case 2 & Case 3 & Case 4 & Case 5 & Case 6 & Case 7 & Case 8 \\
\hline $\begin{array}{l}\text { Uncertainty of } \\
\text { Experiment (\%) }\end{array}$ & 10.47 & 10.69 & 10.95 & 9.02 & 10.77 & 10.91 & 10.52 & 13.51 \\
\hline $\begin{array}{l}\text { Uncertainty of CFD } \\
\text { results (\%) }\end{array}$ & 11.08 & 7.34 & 5.42 & 5.07 & 4.10 & 4.03 & 3.44 & 4.45 \\
\hline
\end{tabular}

The uncertainty of CFD results calculated using Equation 2-8 in the lower brine-water density cases $\left(1.02 \mathrm{~kg} / \mathrm{m}^{3}\right)$ indicate around $11 \%$, compared to the other cases. It is related to how the order of convergence in the whole validation procedure is selected. The order of convergence value is obtained from Case 8 . Density of brine water and pure water are $1.155 \mathrm{~kg} / \mathrm{m}^{3}$ and $1.001 \mathrm{~kg} / \mathrm{m}^{3}$, respectively. The order of convergence value, $\mathrm{p}=1.78$, was determined from three sets of solutions with different mesh sizes. Using the $\mathrm{p}$ value as a general order of convergence in the validation procedure, only two mesh cases (normal and coarse) are used to calculate asymptotic front-head speed. This saves a considerable amount of computing time with reliable accuracies (uncertainty of 3 to $5 \%$ for most of cases) for eight cases of other validation procedures. The uncertainties of CFD results for most of the cases are also shown in Table 2-6.

When computation code is validated with experimental data, it is often tempting to directly compare computational results with experimental data. This comparison, however, can only give a qualitative validation. In the same manner, it can be stated that INL isothermal experimental results are well validated against Fluent CFD results as shown inFigure 2-21. More advanced validations were achieved by using the asymptotic Richardson extrapolation and GCI. Figure 2-22 shows that the CFD code agrees with experiment measurement in stratified flow and also that CFD uncertainty bands agree with experimental uncertainty bands. CFD code is therefore validated for the isothermal experiment in both a qualitative (Figure 2-21) and quantitative way (Figure 2-22).
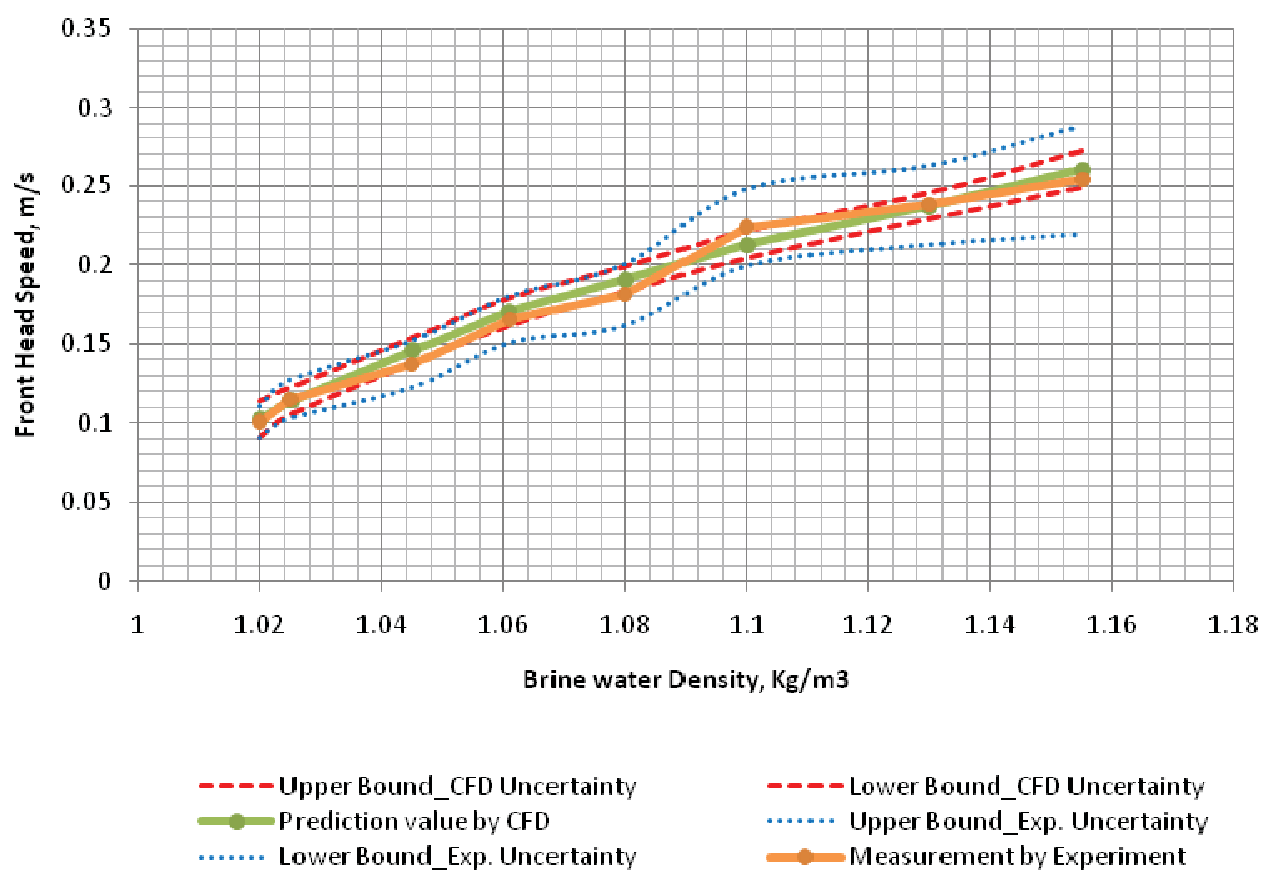

Figure 2-22. Plot of experimental data with uncertainty band and CFD prediction value with code uncertainty band comparison between experiment measurement and previous model (Simpson model [1979] and Benjamin model [1968]) 
A density-driven stratified flow has drawn considerable attention in many fields. A number of researchers have investigated how to predict the current speed or height of flow under different conditions using proper assumptions. A comparison study was conducted wherein two models (Simpson model [1979], Benjamin model [1968]) were reviewed to check the feasibility of the reference theoretical model for this experiment validation. Both models aim to predict current speeds in various conditions. A considerable difference in the two models is whether one takes internal flow (Benjamin model) or external flow (Simpson model) into account. The Benjamin model is considered more feasible in physically capturing the INL isothermal experiment because the experimental condition is designed to investigate internal (in pipe) stratified flow behavior. The Simpson model, which is a function of g'(reduced gravity), d1(height of current flow), and D (total height of channel), predicts front-head speed as follows:

$U_{\text {Simpson }}=f\left(g^{\prime}, d_{1}, D\right)$

$U=1.2 \times\left(g^{\prime} d_{1}\right)$, when $\frac{d_{1}}{D} \ll 0.075$

$U=0.5 \times\left(\frac{d_{1}}{D}\right) \times\left(g^{\prime} d_{1}\right)$, when $0.075<\frac{d_{1}}{D} \leq 0.5$

$U=0.396 \times\left(g^{\prime} d_{1}\right)^{1 / 2}, \frac{d_{1}}{D}=0.5($ Simpson model $)$

Complying with the Simpson model, INL experimental data are thus plotted as

$U=0.65 \sim 0.75 \times\left(g^{\prime} d_{1}\right)^{1 / 2}, \frac{d_{1}}{D}=0.5($ INL experiment $)$

It was then found that INL experimental front-head velocities are approximately 1.6 to 1.87 times larger than those of the Simpson model. However, expressing INL experimental data along with the Simpson model form shows very good agreement with the inviscid model (red dash line) which represents the Benjamin model (see Figure 2-23). The Benjamin model uses internal flow assumption to predict front head speed as follows:

$U_{\text {Benjamin }}=f\left(g^{\prime}, D\right)$

$U=0.5 \times\left(g^{\prime} D\right)^{1 / 2}$, when $\frac{d_{1}}{D}=0.5($ Benjamin model $)$

$U=0.46 \sim 0.55 \times\left(g^{\prime} D\right)^{1 / 2}$, when $\frac{d_{1}}{D}=0.5$ (INL experiment $)$

The INL experimental data agree quite well with the Benjamin model; there is a $10 \%$ deviation. Current INL experiment conditions are physically well-matched with Benjamin model assumptions and conditions. It therefore makes sense to use the Benjamin model to check INL experiment data. 


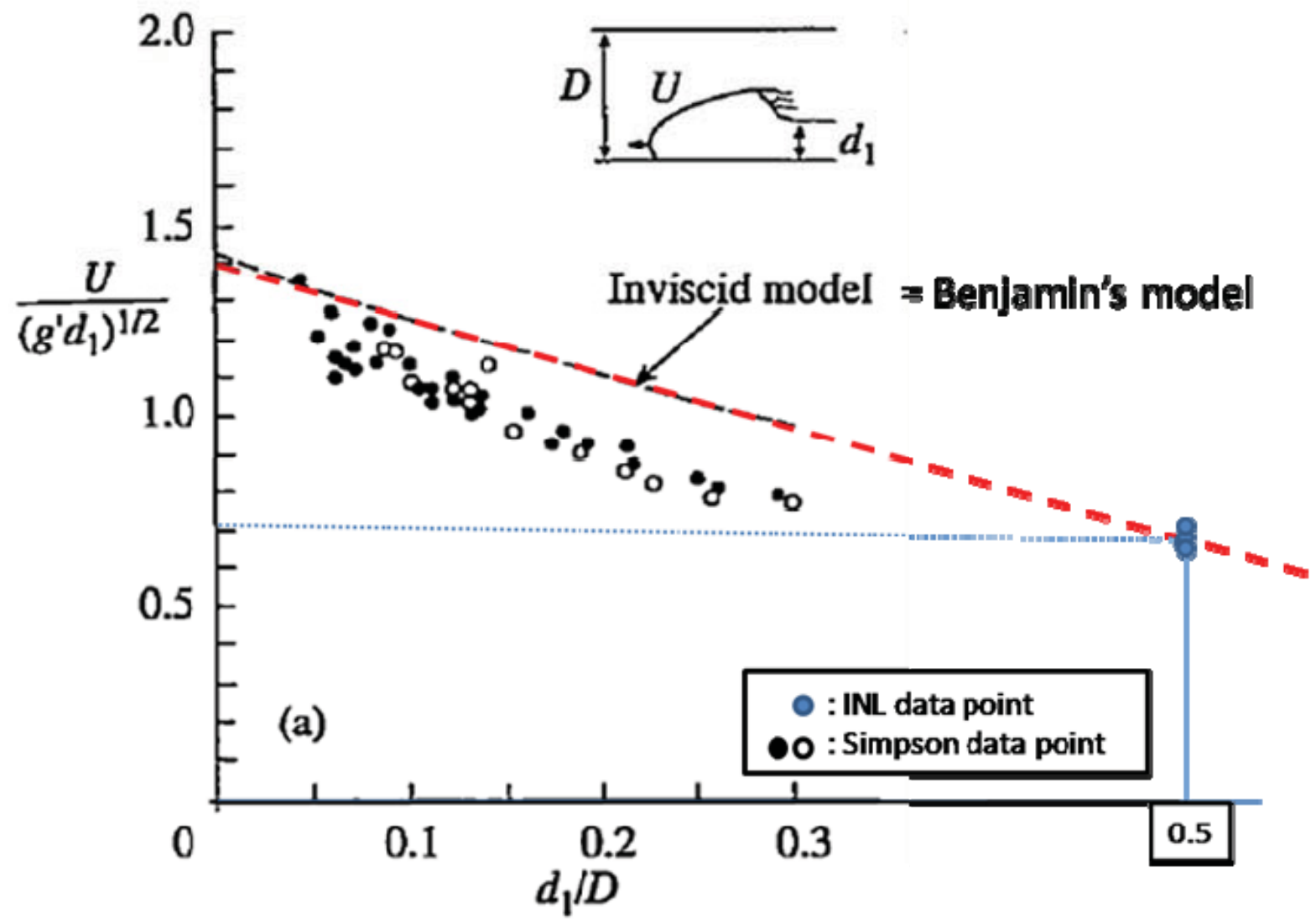

Figure 2-23. Measured front head speed U, scaled with $\left(g^{\prime} d_{1}\right)^{1 / 2}$, as a function of $d_{1} / D$ of INL experimental data and Simpson and Britter data (1979). 


\section{OVERALL SUMMARY}

Several important issues associated with the VHTR air-ingress accident were investigated in FY 2010 as a continuation of FY 2009. The tasks and notable results obtained in FY 2010 are summarized in this section.

Isothermal experiments were designed and conducted. These activities are summarized below.

The objectives of the isothermal experiment were twofold: (1) to understand stratified flow phenomena in the VHTR and (2) to provide experimental data for validating computer codes.

The isothermal experiment is focused on the three flow characteristics unique in the VHTR airingress accident: (1) stratified flow in the horizontal pipe, (2) stratified flow expansion at the pipe and vessel junction, and (3) stratified flow around supporting structures.

Brine and sucrose were used as heavy fluids and water was used as the light fluid. The density ratios were changed between 0.99 and 0.7 .

The experiment shows clear stratified flow between heavy and light fluids, even for the low-density differences.

The stratified flow experimental data based on the circular pipe were compared with the previous theoretical model based on the rectangular channel. Results are in good agreement with the experimental data within a $10 \%$ deviation.

Blind CFD calculations were carried out for comparisons with the experimental data. The FLUENT 6.3.26 was used for the simulation. As a result, the simulation result shows good agreement with the experimental data as the mesh size decreases, indicating that the current CFD code and physical models are appropriate for predicting stratified flow phenomena. 


\section{REFERENCES}

ANSYS, 2008, ICEM CFD-11.0, Manual.

Benjamin, T. B., 1968, "Gravity currents and related phenomena," J. Fluid Mechanics, Vol. 31, pp. 209-248.

Bruauser, S., P. H. Emmett, and T. Teller, 1938, “Adsorption of gases in multimolecular layers," J. Amer. Chem. Soc.,Vol. 60, pp. 309-391.

Contescu, C., 2008 “Current R\&D Activities on Graphite Oxidation at ORNL," Personal Communication, NGNP R\&D Technical Review Meeting, Idaho National Laboratory, May 5-8, 2008.

Engle, G. B., 1977, General Atomics Co. Report, GA-A14690.

Eto, M. and F. B. Growcock, 1983, "Effect of oxidizing environment on the strength of H451, PGX and IG 11 graphites," Carbon, Vol. 21, No. 1, pp. 135-147.

Fagerlund, G., 1973, "Determination of specific surface by BET method," Materjaux et Constructions, Vol. 6, pp. 239-245.

Fuller, E. L., and J. M. Okoh, "Kinetics and mechanisms of the reaction of air with nuclear grade graphites: IG-110," J. Nuclear Materials, Vol. 240, pp. 241-250.

Hinsen, H. K., K. Kuhn, R. Moorman, B. Schlog1, M. Fechter, and M. Mitchel, 2008, "Oxidation experiments and theoretical examinations on graphite materials relevant for the PBMR," Nuclear Engineering and Design, Vol. 238, Issue 11, pp. 3018-3025.

Ishihara, M., T. Iyoku, T. Oku, T. Shibata, J. Sumita, 2004, "Principle Design and Data of Graphite Components," Nuclear Engineering and Design, Vol. 233, pp. 251-260.

Johnson, R. W., 2008, "Modeling strategies for unsteady turbulent flows in the lower plenum of the VHTR," Nuclear Engineering and Design, Vol. 238, pp. 482-491.

Kim, E. S., and H. C. NO, 2006, "Experimental study on the oxidation of nuclear graphite and development of an oxidation model," Journal of Nuclear Materials, Vol. 349, pp. 182-194.

Kim, E. S., H. C. NO, B. Kim, and C. H. Oh, 2007, "Estimation of Graphite and Mechanical Strength Variation of VHTR during Air-ingress Accident," Nuclear Engineering and Design, Vol. 238, Issue 4, pp. 837-847.

Kline, S. J., and F. A. McClintock, 1953, "Describing Uncertainties in Single-Sample Experiments," Mech. Eng., January 1953, p. 3.

Liou, C. P., D. L. Parks, R. R. Schultz, and B. G. Williams, 2005, "Stratified Flows in Horizontal Piping of Passive Emergency Core Cooling Systems," 13th International Conference on Nuclear Engineering, ICONE 13-50450, Beijing, China, May 16-20, 2005.

Liou, C. P., R. R. Schultz, and Y. Kukita, 1997, "Stably Stratified Flow in Closed Conduits," Proceedings of the 5th International Conference on Nuclear Engineering, ICONE5-2024, Nice, France, May 2529, 1997.

Moorman, R., S. Alberici, H. K. Hinssen, A. K. Krussenberg, and C. H. Wu, 1999, "Oxidation behavior of carbon-based materials used for HTGRs and fusion reactors," Adv. Sci. Technol., Vol. 24, pp. 331339.

No, H.C., H. S. Lim, J. Kim, C. H. Oh, L. Siefken, and C. Davis, 2007, "Multi-component diffusion analysis and assessment of GAMMA code and improved RELAP 5 code," Nuclear Engineering and Design, Vol. 237, pp. 997-1008. 
Ogawa, M, 1993, "Mass Transfer with Graphite Oxidation in Gas Mixture Laminar Flow through Circular Tube,” J. At. Energy Soc. Jpn., Vol. 35, Issue 3, p. 245.

Oh, C. H., C. Davis, L. Siefken, R. Moore, H. C. NO, J. Kim, G. C. Park, J. C. Lee, and W. R. Martin, 2006, Development of Safety Analysis Codes and Experimental Validation for a Very High Temperature Gas-Cooled Reactor, Final Report, INL/EXT-06-01362, Idaho National Laboratory, March 2006.

Oh, C. H., E. S. Kim, H. C. NO, and N. Z. Cho, 2008, Experimental Validation of Stratified Flow Phenomena, Graphite Oxidation, and Mitigation Strategies of Air Ingress Accident, FY 2008 Report, INL/EXT-08-14840, Idaho National Laboratory, December 2008.

Oh, C. H., E. S. Kim, S. Kang Hyung, H. C. NO, and N. Z. Cho, 2009, Experimental Validation of Stratified Flow Phenomena, Graphite Oxidation, and Mitigation Strategies of Air Ingress Accident, FY 2008 Report, INL/EXT-09-16465, Idaho National Laboratory, December 2009.

Roache, P. J., 1998, Verification and Validation in Computational Science and Engineering, Hermosa Publishers, Albuquerque, New Mexico, 1998.

Schultz, R. R., et al., 2006, Next Generation Nuclear Plant Methods Technical Program Plan, INL/EXT-06-11804, September 2006.

Simpson, J. E., and R. E. Britter, 1979, "The dynamics of the head of a gravity current advancing over a horizontal surface,” J. Fluid Mech., Vol. 94, Part 3, pp. 477-495, 1979.

Takeda T., 1997, Air Ingress Behavior during a Primary-pipe Rupture Accident of HTGR, JAERI-1338, Japan Atomic Energy Research Institute, 1997.

Takeda, T. and M. Hishida, 1996, "Studies on Molecular Diffusion and Natural Convection in a Multicomponent Gas System," International Journal of Heat and Mass Transfer, Vol. 39, No. 3, pp. 527-536, 1996.

Wichner, R. P., 1976, Oak Ridge National Laboratory Report, ORNL/TM-5534.

Yan, et al., 2008, "A Study of Air Ingress and its Prevention in HTGR," Nuclear Technology, Vol. 163, September 2008.

Yih, C. S., 1980, Dynamics of Nonhomogeneous Fluids, Macmillan. 
Appendix A

\section{Isothermal Stratified Flow Experiment Facility Schematics}




\section{Appendix A}

\section{Isothermal Stratified Flow Experiment Facility Schematics}

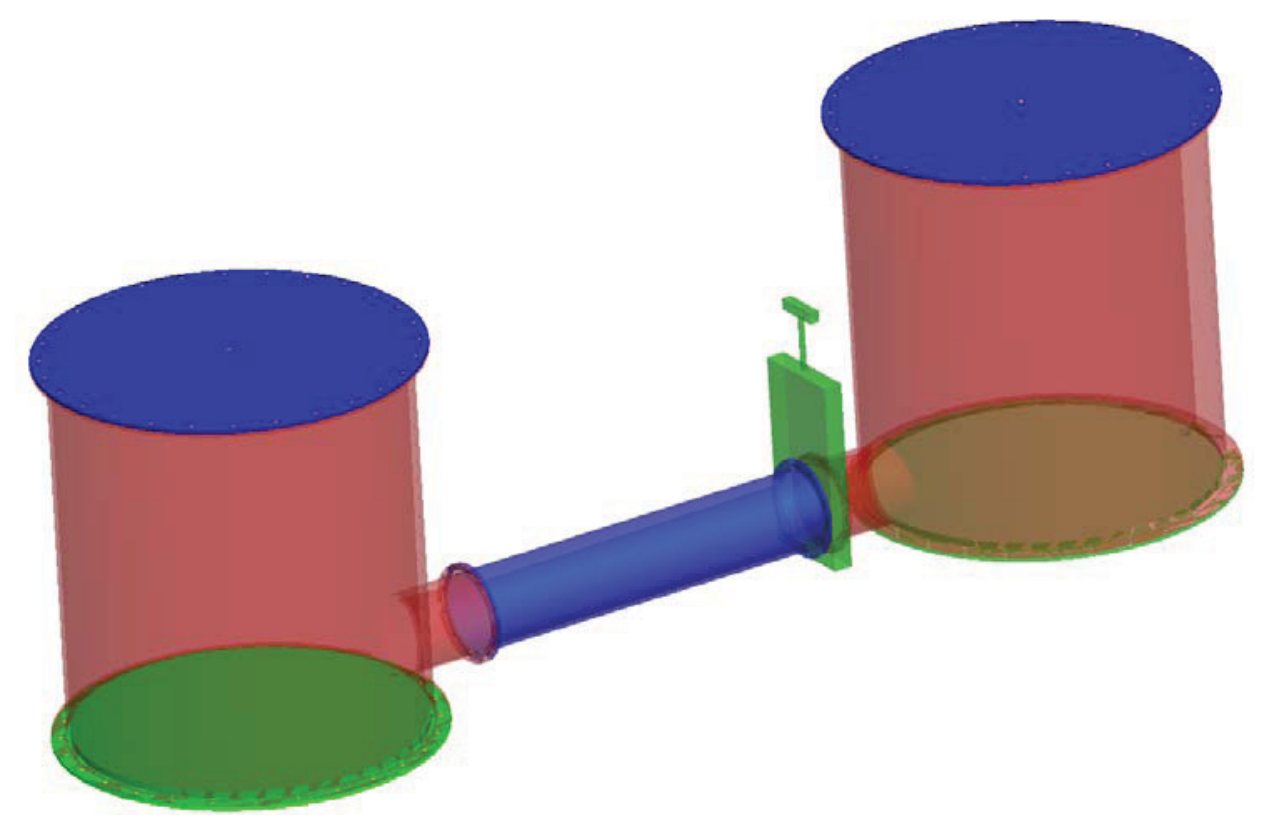

Figure A-1. Double-ended guillotine break facility assembly with knife gate valve. 

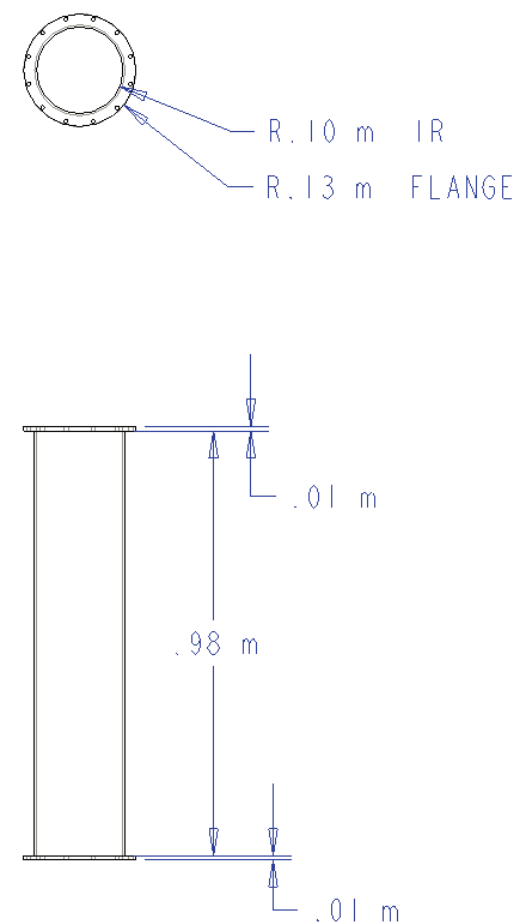

$5 \mathrm{~mm}$ PIPE THICKNESS

PIPE FLANGE HAS I 2 EQUALLY SPACED

25/64" HOLES 0.122 m FROM AXIS

Figure A-2. Horizontal pipe dimensions.
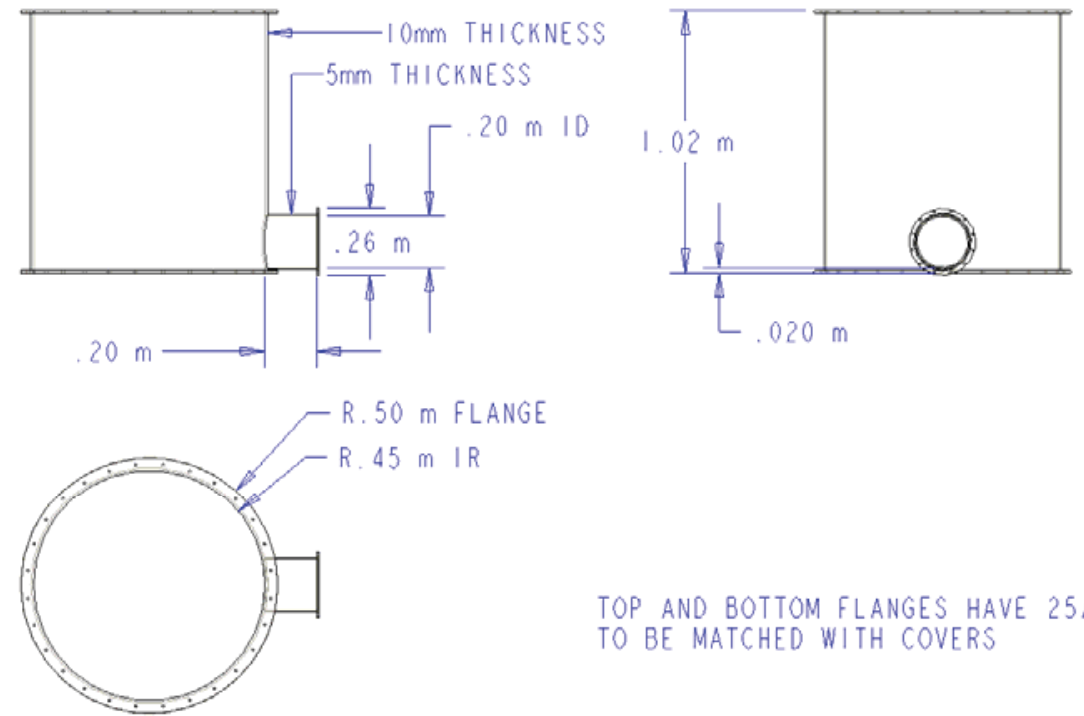

TOP AND BOTTOM FLANGES HAVE 25/64" HOLES

TO BE MATCHED WITH COVERS

FLANGES $10 \mathrm{~mm}$ THICK

CUT AN O-RING GROVE IN THE TOP FLANGE

OR SPEC APPROPRIATE GASKET

OUTLET PIPE I.D. IS TO BE $20 \mathrm{~mm}$ FROM

BOTTOM OF FLANGE

Figure A-3. Flanged tank dimensions. Tanks have covers on both top and bottom to facilitate cleaning. 


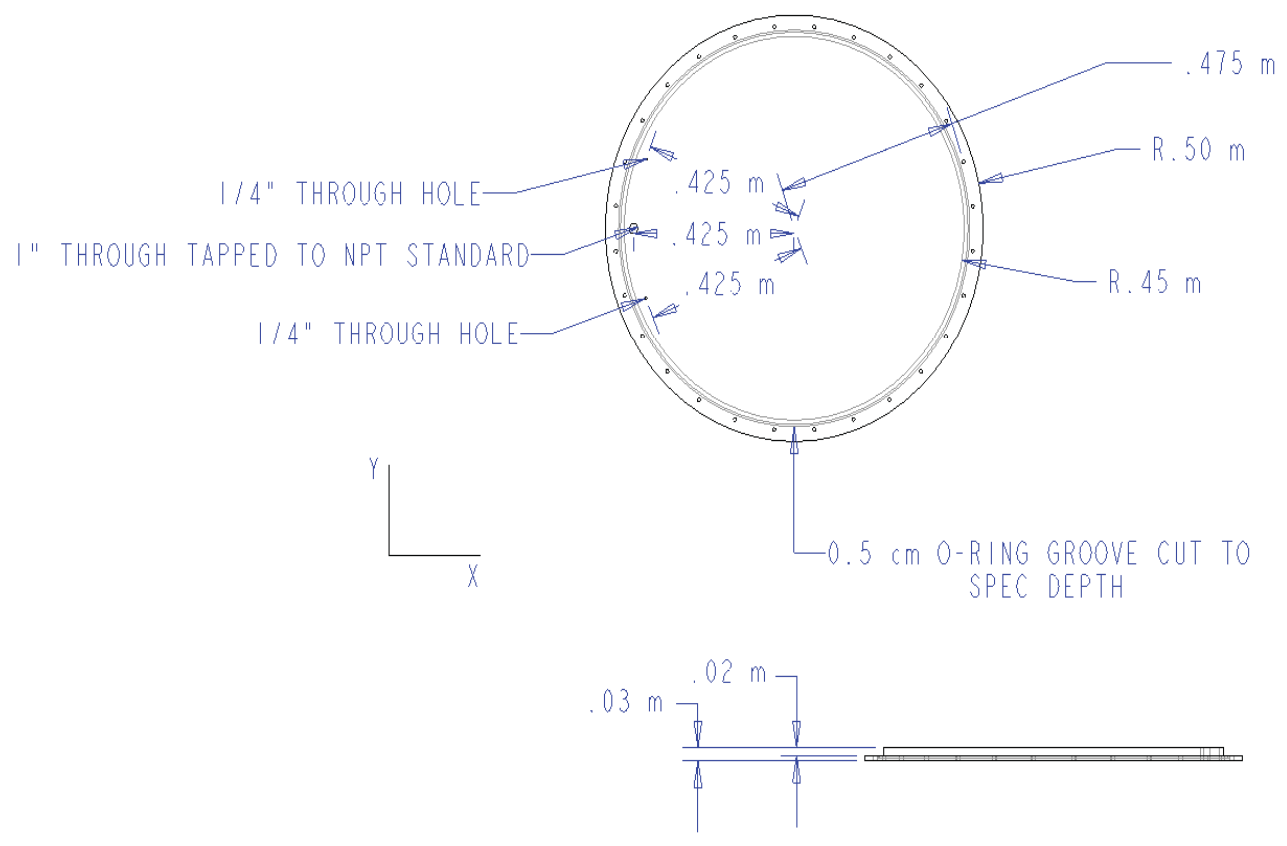

Figure A-4. Bottom tank cover.

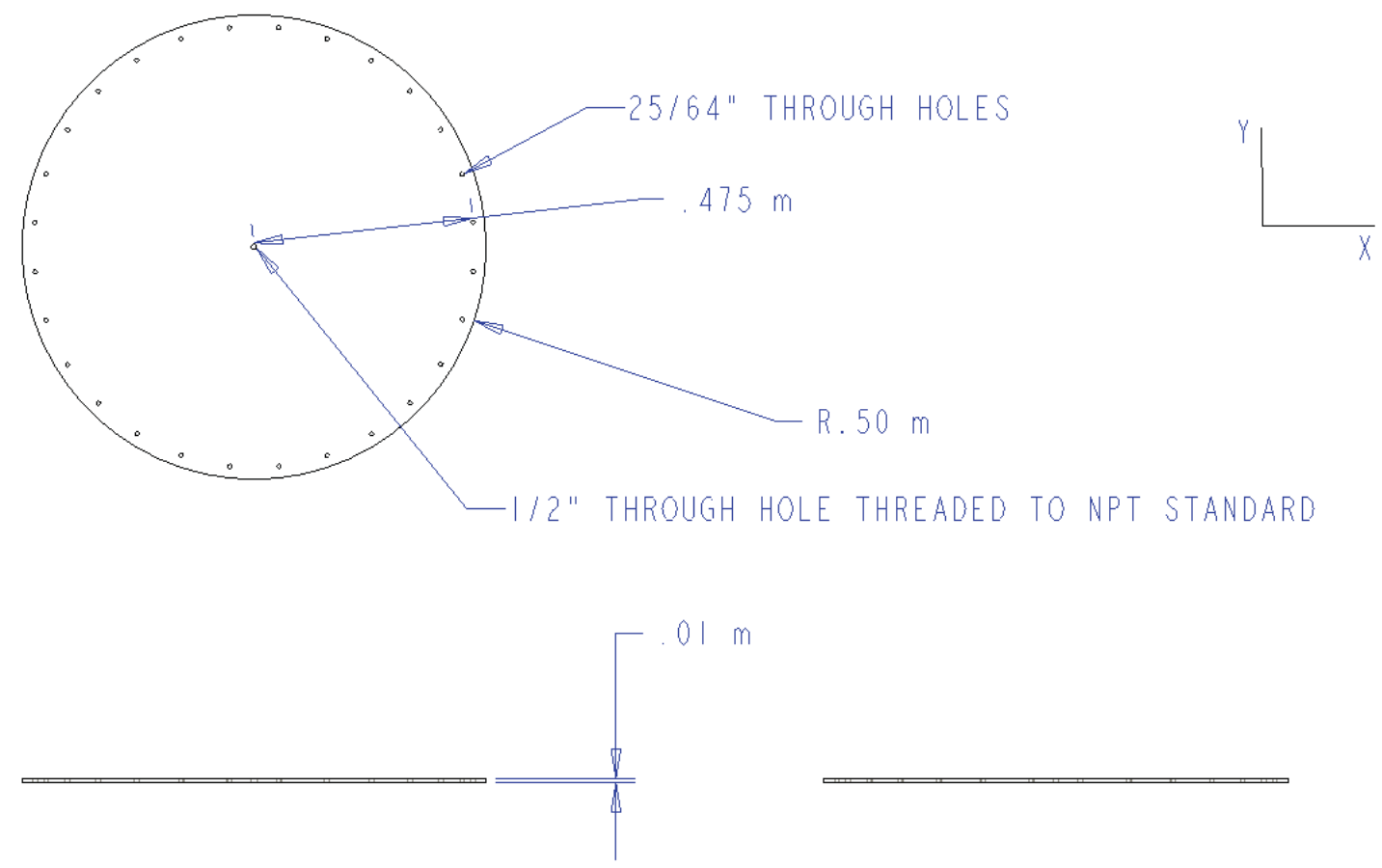

Figure A-5. Top tank cover. 
Appendix B

\section{Knife Valve Supporter Load Analysis}




\section{Appendix B}

\section{Knife Valve Supporter Load Analysis}

This perfunctory analysis includes basic load calculations to determine the resultant forces that would be seen at the floor bolts because of a $200 \mathrm{lbf}$ lateral force at the top of the valve, which represents a worst-case load induced by an average-sized person leaning against the valve. It also includes a finite element analysis to determine the stresses in the assembly and a weld analysis to determine the length of weld required at the assembly interfaces.

The knife-valve-brace assembly is shown in Figure B-1. The brace is built around a 3/4 in. A36 steel plate which mounts to the knife valve flange [A]. Six $1 / 2$ in. bolts [B] are used to sandwich the plate between two $4 \times 4 \times 1 / 4$ in. A36 steel L-beams [C]. These L-beams are welded to two more A36 L-beams [D] which have through holes on the base flange for a $24 \times 24 \mathrm{in}$. bolt pattern. These outer L-beams are then attached, via nuts and washers sandwiching the upper and lower faces of the lower L-beam flange, to four $1 / 2$ in. bolts [E] anchored into the concrete floor with Hilti Kwik Bolt 3 expansion anchors. The bolted connection to the base flange allows for height adjustment on all four corners of the brace.

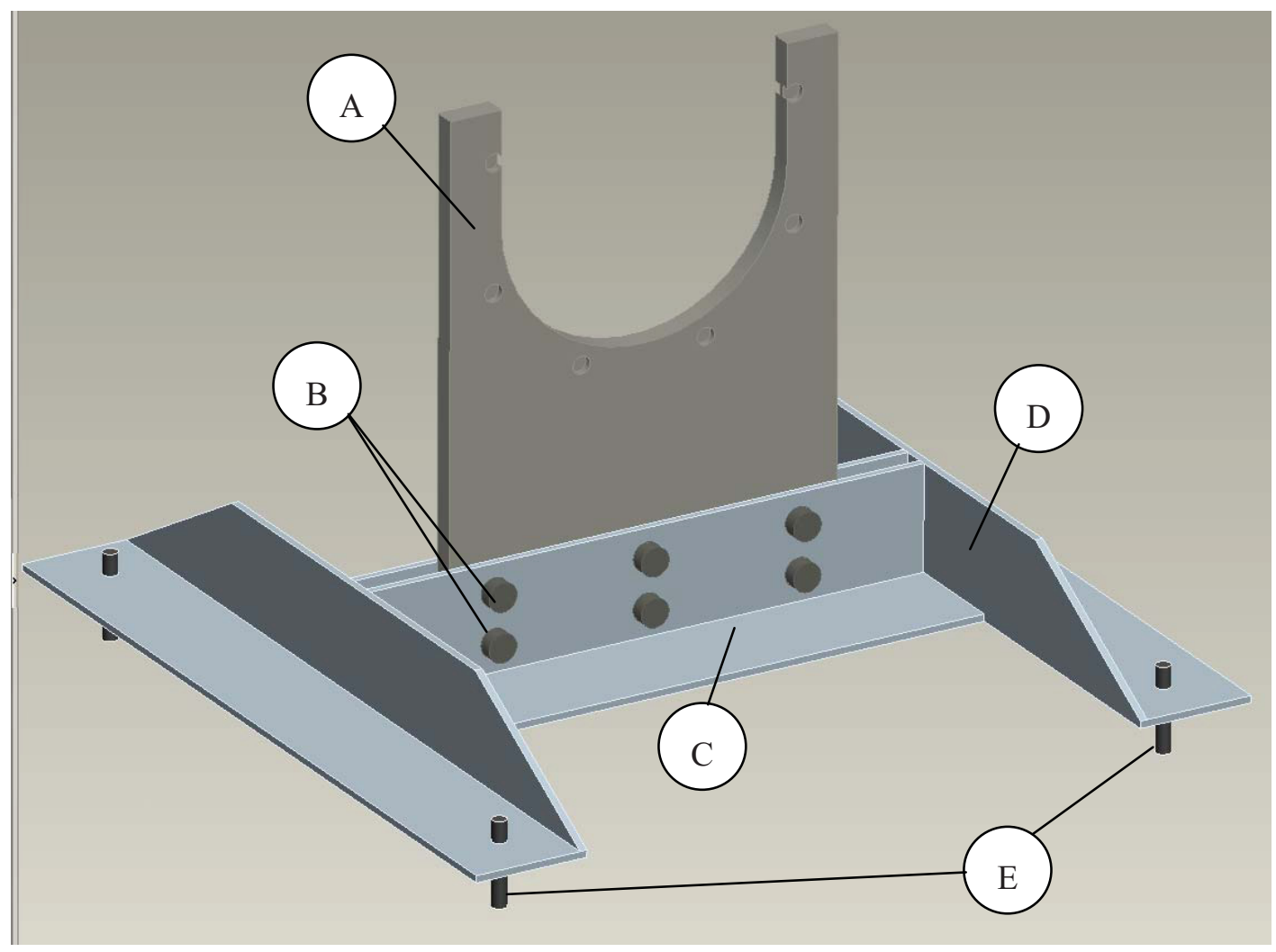

Figure B-1. Knife valve brace.

The part was modeled and analyzed in Pro/Engineer and Pro/Mechanica, respectively. Also, various hand calculations of simplified models were performed to compare against the Pro/Mechanica model. 
For example, one scenario would be applying a 4,800 in-lbf moment (400 ft-lbf) to the frame and checking the reaction forces at the corners. It is easily seen that for a 24-in. base bolt pattern, the reactions at each bolt would be $100 \mathrm{lbf}$ (see Figure B-2 and Eqs.B-1, B-2).

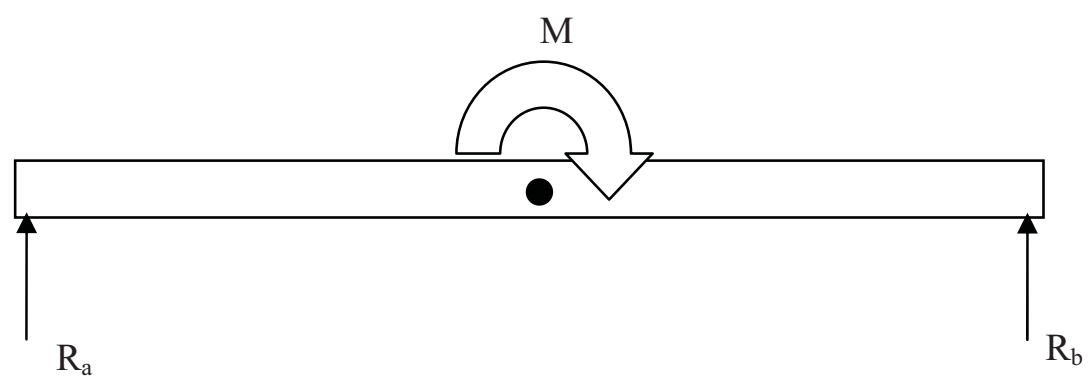

Figure B-2. Simple moment diagram.

$R_{a}=\frac{M}{l}$. (Blodgett and Omer [1991])

$R_{b}=\frac{-M}{l}$

Applying the same moment (4,800 in.-lbf) to the Pro/E model yields the reaction forces shown in Figure B-3. In summary, there is tension on the bolts nearest the person-loading of approximately $150 \mathrm{lbf}$ vertical, and the two bolts furthest from the person-loading the frame see a compressive force of $\sim 197 \mathrm{lbf}$. Each bolt also sees a shear force of $\sim 50 \mathrm{lbf}$. 


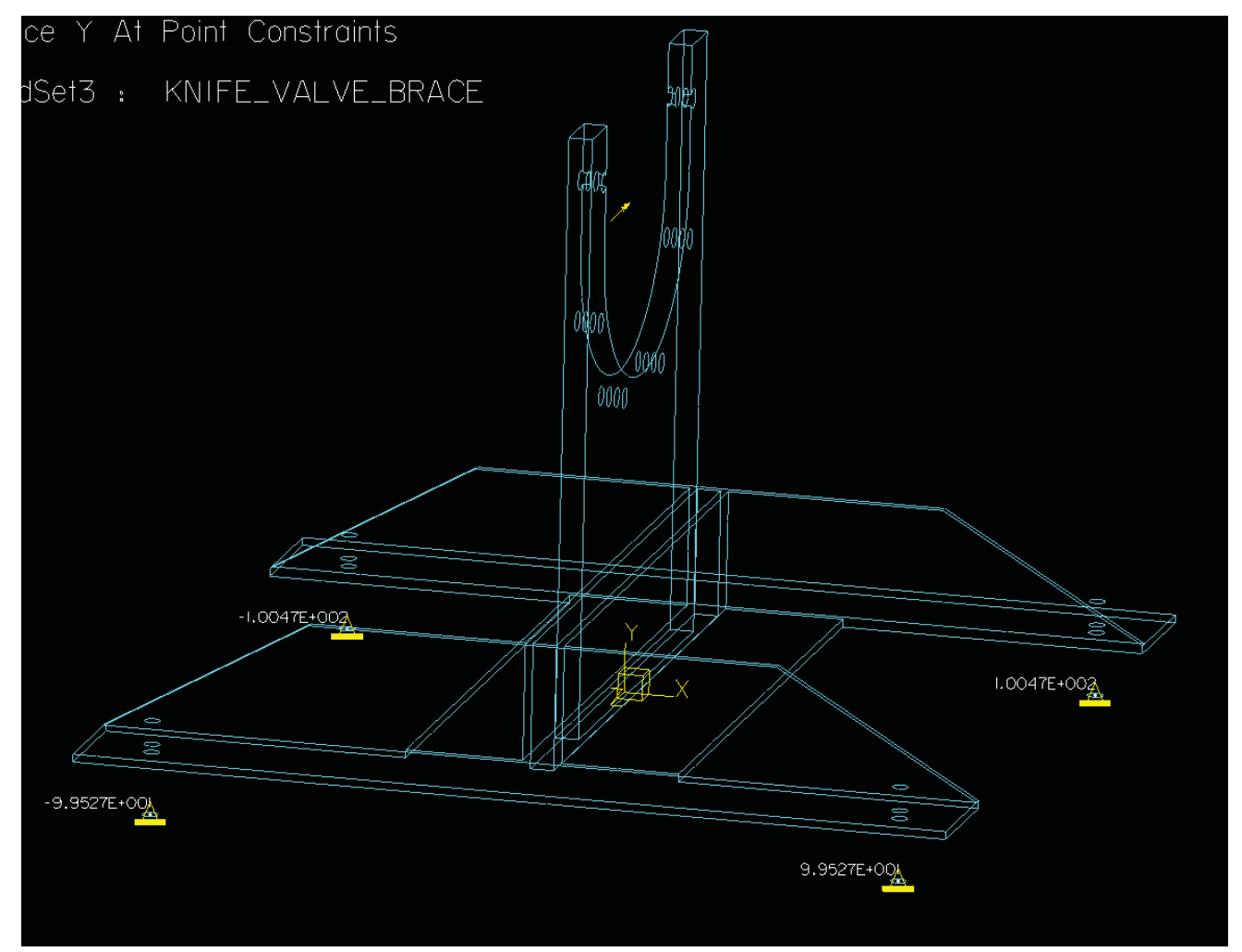

Figure B-3. Simple moment resultant forces (lbf).

Next, applying the lateral force of $200 \mathrm{lbf}$ at the top of the valve (with the corresponding moment of 4,800 in.-lbf) and an additional $100 \mathrm{lbf}$ vertical load from the valve itself, the resultant forces seen by the anchor bolts are shown in Figure B-4. It can be seen that this is nearly identical to the previous load case because of the symmetric bolt pattern. 


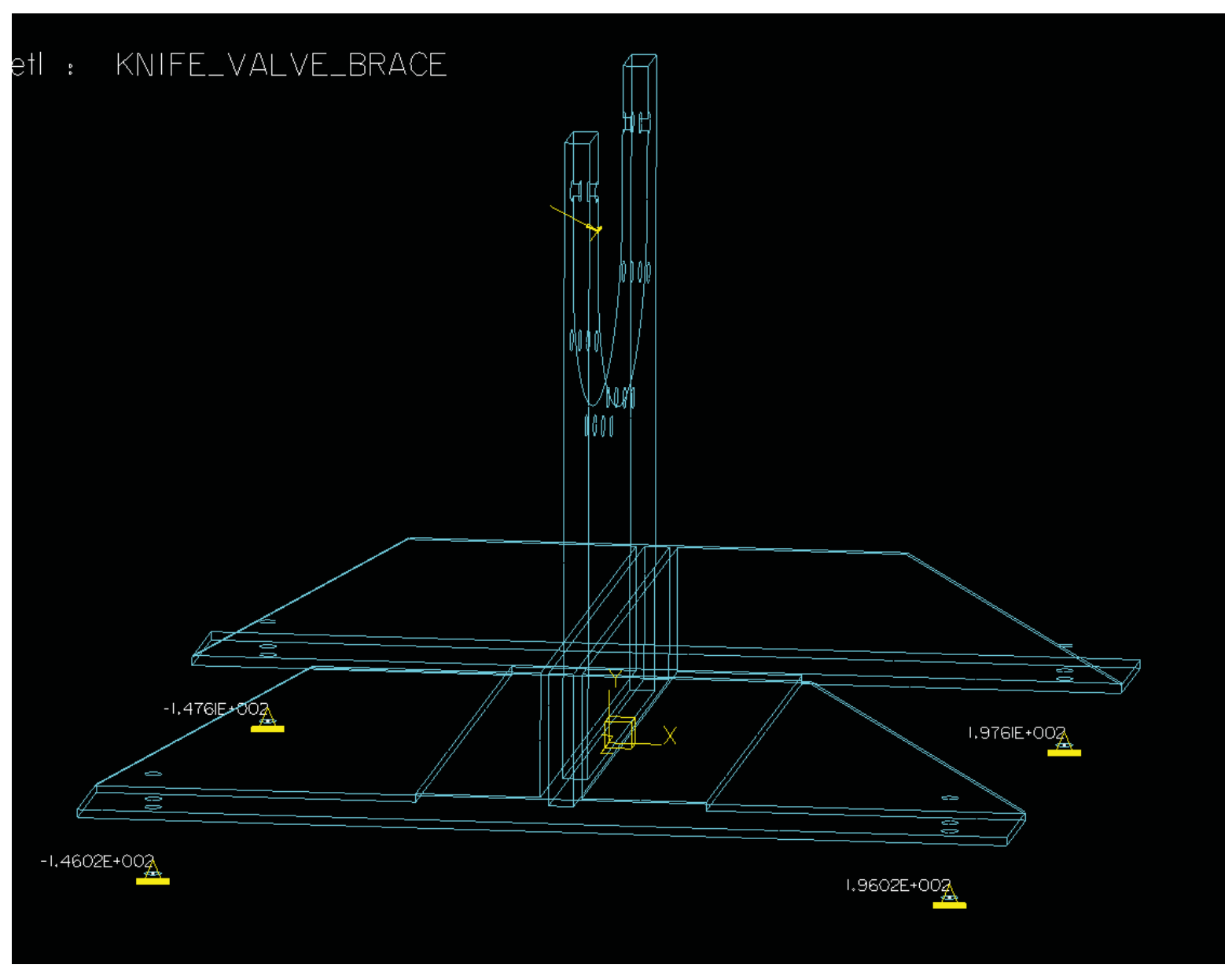

Figure B-4. Resultant forces from simulated loading (lbf).

A weld analysis was performed per Blodgett to determine the minimum weld length required at the interface between the lateral L-beams [C] and the longitudinal L-beams [D]. It was determined that the minimum weld length for one $4 \times 4$ in. L-beam under the simulated load is $0.07 \mathrm{in}$. Therefore, it will call out an intermittent $1 / 4$ in. fillet weld in two places on each face of the L-beam.

A bolt pull-out analysis was performed using the Hilti anchor design guide (2005) as a reference. Using a Hilti Kwik Bolt 3 expansion anchor with a one-half inch bolt diameter and an embedded depth of $2-1 / 4$ inches, and assuming 2,000 psi concrete, the maximum allowable load is seen to be 1,235 $\mathrm{lbf}$ in tension and 2235 in shear. Given the simulated loading condition of a load being applied at the top of the valve body (36 in. above the base), it would require an $800 \mathrm{lbf}$ lateral force to generate this load.

Figure B-5 shows the stresses in the brace as a result of the applied simulated loading. The stresses in the vertical plate where it meets the lateral supports can be seen to be approximately 5,000 psi. This is compared to stresses calculated using first principles (Mc/I) to be 5,640 psi. It is evident that there is agreement between the analytical and computational models. 


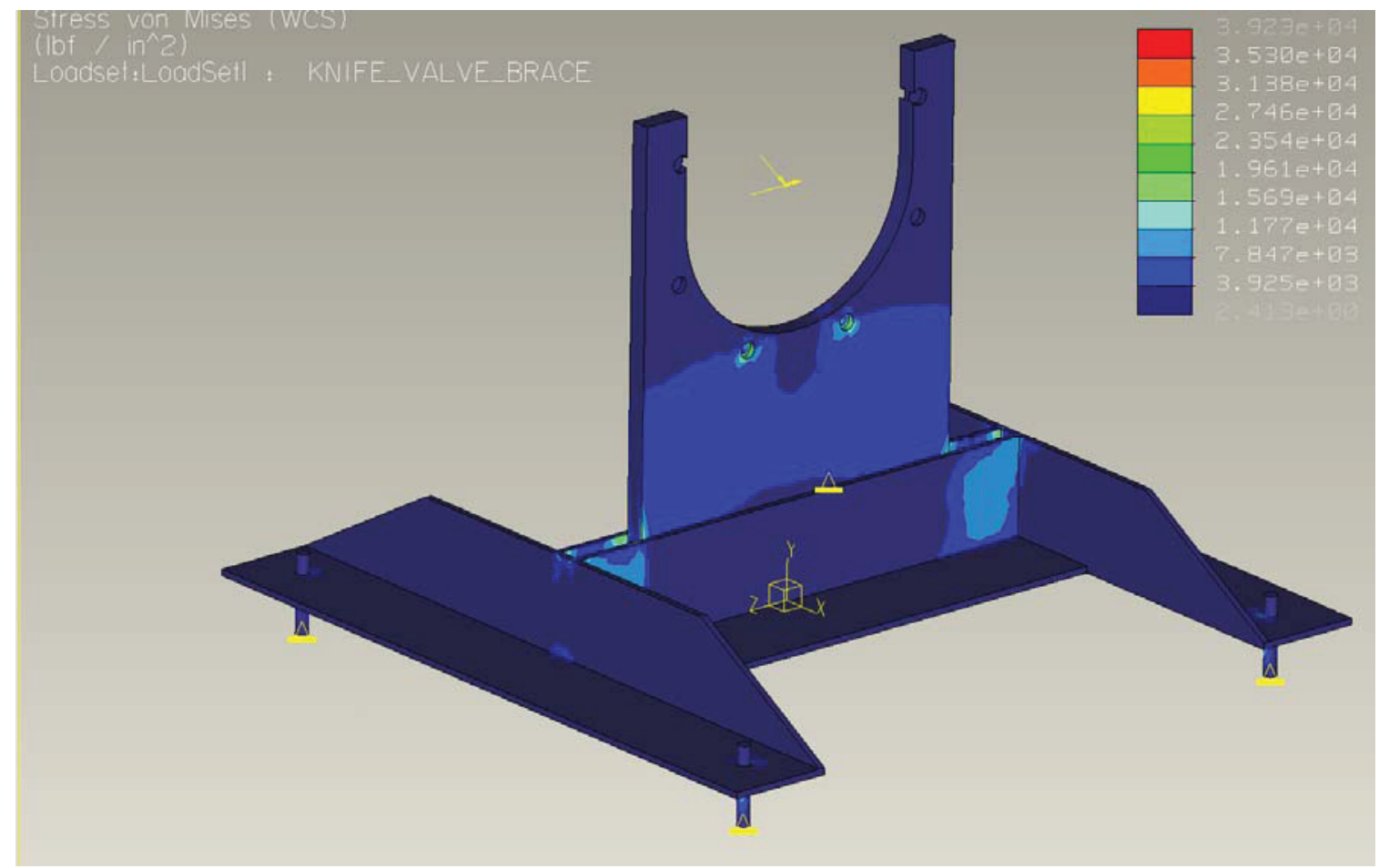

Figure B-5. Local frame stresses from simulated load (psi).

As all components and interfaces adequately carry the assumed worst-case load, this frame is seen to be adequate for the purpose of holding the knife valve for the air-ingress experiment.

\section{References}

Blodgett, Omer W., Design of Welded Structures, The James F. Lincoln Arc Welding Foundation, Cleveland, Ohio, $14^{\text {th }}$ printing, 1991.

Hilti, North America Kwik Bolt 3 Product Technical Guide Supplement, 2005, Hilti (Canada)

Corporation. 